\title{
Transcription factor Ebf1 regulates differentiation stage-specific signaling, proliferation, and survival of $B$ cells
}

\author{
Ildiko Györy, ${ }^{1,3}$ Sören Boller, ${ }^{1,3}$ Robert Nechanitzky, ${ }^{1,3}$ Elizabeth Mandel, ${ }^{1}$ Sebastian Pott, ${ }^{2}$ \\ Edison Liu, ${ }^{2}$ and Rudolf Grosschedl ${ }^{1,4}$ \\ ${ }^{1}$ Department of Cellular and Molecular Immunology, Max Planck Institute of Immunobiology and Epigenetics, 79108 Freiburg, \\ Germany; ${ }^{2}$ Cancer Biology and Pharmacology, Genome Institute of Singapore, 138672 Singapore
}

The transcription factor Ebf1 is an important determinant of early B lymphopoiesis. To gain insight into the functions of Ebf1 at distinct stages of differentiation, we conditionally inactivated Ebf1. We found that Ebf1 is required for the proliferation, survival, and signaling of pro-B cells and peripheral B-cell subsets, including B1 cells and marginal zone $B$ cells. The proliferation defect of Ebf1-deficient pro-B cells and the impaired expression of multiple cell cycle regulators are overcome by transformation with $\mathrm{v}$-Abl. The survival defect of transformed $E b f 1^{f l f f l}$ pro-B cells can be rescued by the forced expression of the Ebf1 targets $c-M y b$ or $B c l-x_{L}$. In mature B cells, Ebf1 deficiency interferes with signaling via the B-cell-activating factor receptor (BAFF-R)- and B-cell receptor (BCR)-dependent Akt pathways. Moreover, Ebf1 is required for germinal center formation and class switch recombination. Genome-wide analyses of Ebf1-mediated gene expression and chromatin binding indicate that Ebf1 regulates both common and distinct sets of genes in early and late stage B cells. By regulating important components of transcription factor and signaling networks, Ebf1 appears to be involved in the coordination of cell proliferation, survival, and differentiation at multiple stages of B lymphopoiesis.

[Keywords: Ebf1; c-Myb; B-cell differentiation; BCR signaling; Ig class switch recombination; germinal center B cells] Supplemental material is available for this article.

Received January 13, 2012; revised version accepted February 23, 2012.

B lymphopoiesis is a complex process of differentiation that converts lineage-committed progenitors into highly specialized antibody-secreting plasma cells. In the bone marrow, differentiation of lymphoid progenitor cells into pro-B cells involves the rearrangement of the immunoglobulin heavy chain (IgH) locus and proliferation in response to interleukin-7 (IL-7) (Dias et al. 2005; Nutt and Kee 2007; Malin et al. 2010). Successful IgH gene rearrangement generates pre-B cells that express the pre$\mathrm{B}$-cell receptor (pre-BCR) and undergo rearrangement of the Ig light chain loci to further differentiate into immature B cells. These cells egress into the peripheral lymphoid organs and are competent to respond to antigenic stimulation via the BCR. Survival of circulating mature B cells is dependent on tonic BCR signals via the PI3 kinase (PI3K)/Akt pathway and on B-cell-activating factor receptor (BAFF-R) signals (Kraus et al. 2004; Mecklenbrauker et al. 2004; Srinivasan et al. 2009). Antigenic stimulation

\footnotetext{
${ }^{3}$ These authors contributed equally to this work.

${ }^{4}$ Corresponding author.

E-mail grosschedl@ie-freiburg.mpg.de.

Article published online ahead of print. Article and publication date are online at http://www.genesdev.org/cgi/doi/10.1101/gad.187328.112. Freely available online through the Genes \& Development Open Access option.
}

of $B$ cells results in the formation of germinal center (GC) B cells that undergo extensive proliferation, somatic hypermutation of Ig genes, and IgH class switch recombination (Klein and Dalla-Favera 2008).

Early specification of the B-cell lineage program and loss of alternate lineage potential are regulated by a network of transcription factors, including E2A, Ebf1, and Pax5 (for review, see Nutt and Kee 2007; Mandel and Grosschedl 2010). Loss-of-function analyses of Ebf1 and E2a (Tcf3) in mice indicated that both transcription factors are necessary for the generation of pro-B cells that undergo rearrangement of the IgH gene locus (Bain et al. 1994; Zhuang et al. 1994; Lin and Grosschedl 1995). Gain-of-function and genetic bypass experiments, in which Ebfl was ectopically expressed in hematopoietic progenitor cells from wild-type mice or mutant mice lacking transcription factors Ikaros or Pu.1, showed that Ebf1 is involved in specifying the B-cell lineage (Zhang et al. 2003; Medina et al. 2004; Pongubala et al. 2008; Reynaud et al. 2008; Zandi et al. 2008). In addition, Ebf1 was found to repress alternative cell fate determinants (Pongubala et al. 2008; Thal et al. 2009; Lukin et al. 2011). Early B lymphopoiesis also depends on the functions of Myb (c-Myb) and Miz1, 
which appear to act upstream of Ebf1 and regulate survival and differentiation of pro-B cells (Fahl et al. 2009; Greig et al. 2010). Myb has been shown to regulate the expression of the $\alpha$ chain of the IL-7 receptor and cell survival via an IL-7R-independent pathway (Fahl et al. 2009; Greig et al. 2010). Transcription factors of the Foxo family also regulate the expression of IL-7R, whereby they act in an autoregulatory loop in which IL-7R signaling results in PI3K-dependent phosphorylation and inactivation of Foxol and cell cycle progression (Dengler et al. 2008; Kerdiles et al. 2009). Foxol has been identified as a direct target of both Ebf1 and E2A and might act downstream from these lineage determinants (Zandi et al. 2008; Lin et al. 2010; Treiber et al. 2010).

Many of the transcription factors that regulate early steps in B lymphopoiesis are also required for peripheral B-cell functions. In particular, Myb has been shown to regulate survival of splenic $B$ cells and the expression of the BAFF-R (Thomas et al. 2005). The survival of splenic B cells is also regulated by the PI3K arm of the BCR pathway, which results in the inactivation of Foxo transcription factors (Dengler et al. 2008; Srinivasan et al. 2009). The proliferative response of splenic B cells to lipopolysaccharide (LPS) involves the function of Pax5, which also represses alternative lineage markers in mature B cells (Wakatsuki et al. 1994; Horcher et al. 2001). E2A has a relatively minor role in the generation and survival of splenic B cells (Kwon et al. 2008). However, E2A is required for the formation of GC B cells, and the E47 isoform of $\mathrm{E} 2 \mathrm{~A}$ regulates $\mathrm{BCR}$ editing upon exposure to self-antigen (Kwon et al. 2008; Beck et al. 2009). Moreover, class switch recombination in GC B cells depends on the regulation of activation-induced deaminase (Aid) by Foxol and IRF4, the activation of I promoters located upstream of the IgH constant region gene segments, and the function of enhancers in the locus control region (LCR) at the $3^{\prime}$ end of the IgH locus (Wolniak et al. 2004; Klein and Dalla-Favera 2008; Stavnezer et al. 2008). Despite the extensive analysis of the role of Ebf1 in the specification of the B-cell lineage, the early developmental block in Ebf1-null mice has obscured its functions at later stages of B lymphopoiesis.

\section{Results}

Ebf1 regulates early B lymphopoiesis in a network of multiple transcription factors

To inactivate Ebf1 conditionally at various stages of B-cell differentiation, we generated mice carrying a targeted allele of Ebf1 in which exons \#2 and \#3, encoding part of the DNA-binding domain, were flanked by $\operatorname{lox} P$ sites (Supplemental Fig. S1A). The Neo cassette of the targeting construct, flanked by Frt sites, was permanently deleted by crossing $E b f 1^{+/ f 1, N e o}$ mice with Act-FLPe mice that express the Flp recombinase (Rodriguez et al. 2000). Successful targeting of the Ebf1 locus was determined by DNA blot and PCR analysis (Supplemental Fig. S1B,C). To confirm the loss of Ebf1 function upon deletion by Cre-mediated recombination of the loxP sites, we crossed
$E b f 1^{f l / f 1}$ mice with the $m b 1^{C r e}$ strain, which expresses Cre recombinase in early pro-B cells (Hobeika et al. 2006). Analysis of the bone marrow of $E b f 1^{f 1 / f 1} \mathrm{mb} 1^{\text {Cre }}$ mice by flow cytometry revealed a block of B-cell differentiation at the pre-pro-B-cell stage, which is identical to that observed in $E b f 1^{\Delta / \Delta}$-null mice (Supplemental Fig. S1D; Lin and Grosschedl 1995). This early developmental block in $E b f 1^{f l / f l} m b 1^{C r e}$ mice was not rescued by the expression of a $\mathrm{TgBcl} 2$ transgene (Supplemental Fig. S1D).

To examine the function of Ebf1 at various stages of B-cell differentiation, we crossed $E b f 1^{+/ f l}$ mice with $R E R T^{C r e}$ mice in which Ebf1 can be deleted in a tamoxifeninducible manner (Guerra et al. 2003). Within 3-6 d after tamoxifen treatment of $E b f 1^{f l / f 1} R E R T^{C r e}$ mice or pro-B-cell cultures, the protein and RNA expression of Ebf1 was markedly reduced in the spleen, bone marrow, fetal liver, and pro-B-cell cultures (Fig. 1A; Supplemental Fig. S1E-G). Flow cytometric analysis of Ebf $1^{f l / f 1} R E R T^{\text {Cre }}$ bone marrow revealed a markedly reduced frequency of $\mathrm{B} 220^{\text {int }} \mathrm{CD} 43^{-}$pre-B cells and increased numbers of recirculating B220 hi CD $43^{-}$B cells, as compared with $E b f 1^{+/ f l}$ $R E R T^{C r e}$ bone marrow (Fig. 1B). We also observed a developmental block of Ebf1-deficient pre-B cells in vitro. In fetal liver cell cultures from $E b f 1^{f l / f l} R E R T^{C r e} \mathrm{TgBcl}$ mice that were tamoxifen-treated and sorted for $\mathrm{CD} 19^{+} \mathrm{CD} 43^{+}$ c-kit ${ }^{-}$early stage B cells, we found fewer CD2 $5^{+} \kappa^{-}$pre-B cells and CD25- $\mathrm{K}^{+}$immature B cells than in corresponding $E b f 1^{+/ f 1} R E R T^{C r e} \mathrm{TgBcl} 2$ cultures (Fig. 1C). Consistent with a block in the differentiation of pre-B cells, we also detected fewer Igא germline transcripts (GLTs) in Ebf1-deficient cell cultures (Fig. 1D).

Differentiation of pre-B cells is dependent on transcription factors Foxo1, Irf4, and Irf8, whereby Foxo1 regulates $I L-7 R \alpha$ expression in pro-B cells and $I g \kappa$ rearrangement in pre-B cells (Amin and Schlissel 2008; Dengler et al. 2008; Herzog et al. 2008). Irf4 and Irf8 inhibit cell proliferation and promote $\kappa$ rearrangement by binding to the $\kappa 3^{\prime}$ enhancer (Lu et al. 2003; Lazorchak et al. 2006; Johnson et al. 2008). Ebf1-deficient pro-B cells showed impaired expression of Foxo1 and additional Ebf1-bound transcription factor genes, including Irf4, Irf8, Tcf3 (E2a), Pax5, Aiolos (Ikzf3), Ikaros (Ikzf1), Myb, and Mybl2 (Fig. 1E; Supplemental Fig. S1H; Lin et al. 2010; Treiber et al. 2010). We also observed reduced expression of $I L-7 R \alpha$ and Bcl211. We confirmed direct binding of Ebf1 to Irf4, Irf8, Myb, Mybl2, and Bcl211 sequences by chromatin immunoprecipitation (ChIP) analysis (Fig. 1F). Moreover, previous ChIP-seq analysis of pro-B cells indicated that Ebf1 peak regions in the Irf4 and Irf8 loci overlapped with regions of $\mathrm{H} 3 \mathrm{~K} 4 \mathrm{me} 2$ chromatin modification (Fig. 1G; Lin et al. 2010; Treiber et al. 2010). No Ebf1 binding was detected at the $I L-7 R \alpha$ and $I g \kappa$ loci (data not shown), suggesting that the decreased $I L-7 R \alpha$ and $\kappa$ germline transcription in Ebf1-deficient pro-B cells is likely due to the impaired expression of Foxo1 and Irf4/8, respectively. Thus, Ebf1 regulates early B-cell differentiation not only in combination with E2A and Pax5, but in an extended network that includes Foxo and Irf transcription factors. 
Györy et al.

A
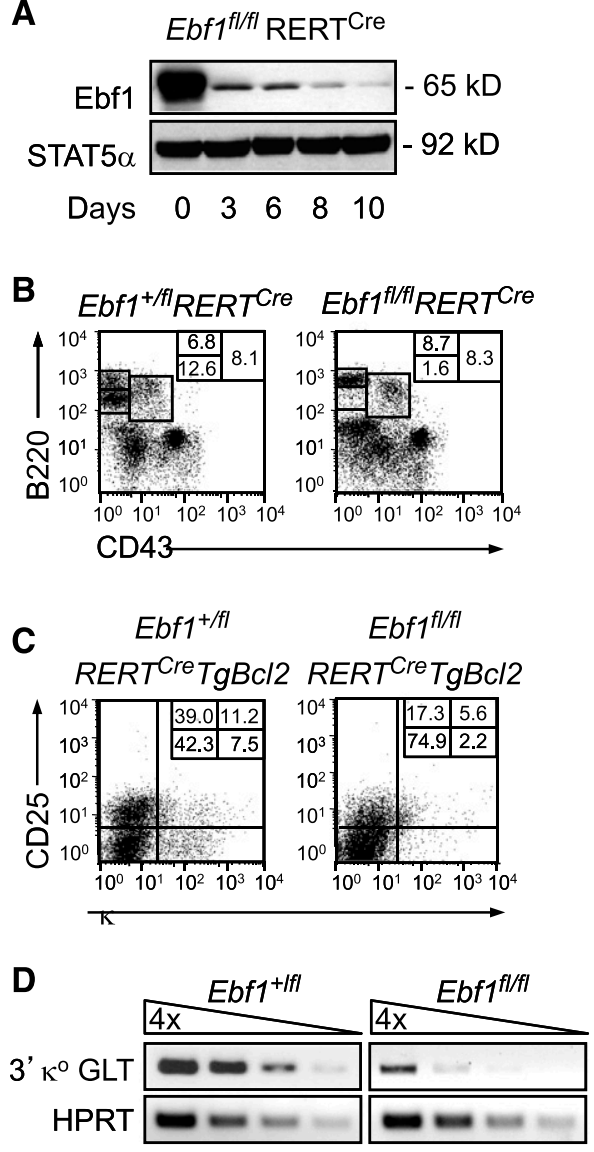

E

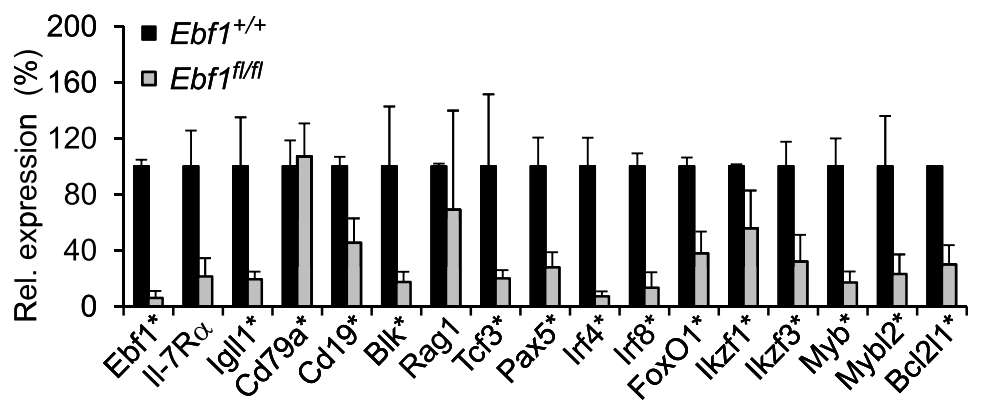

$\mathbf{F}$

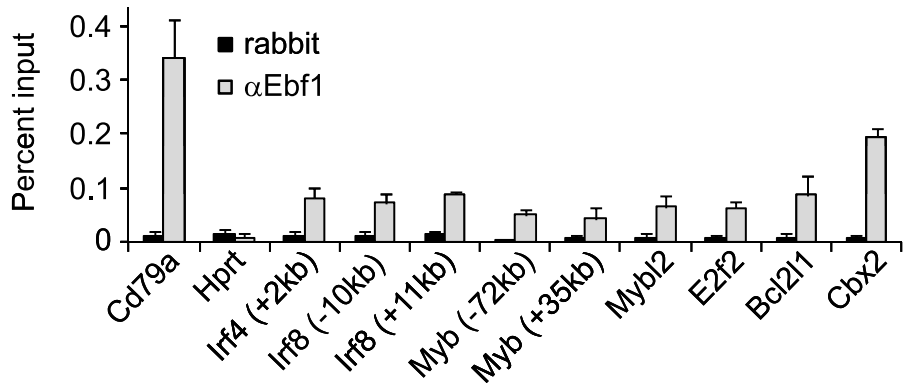

G

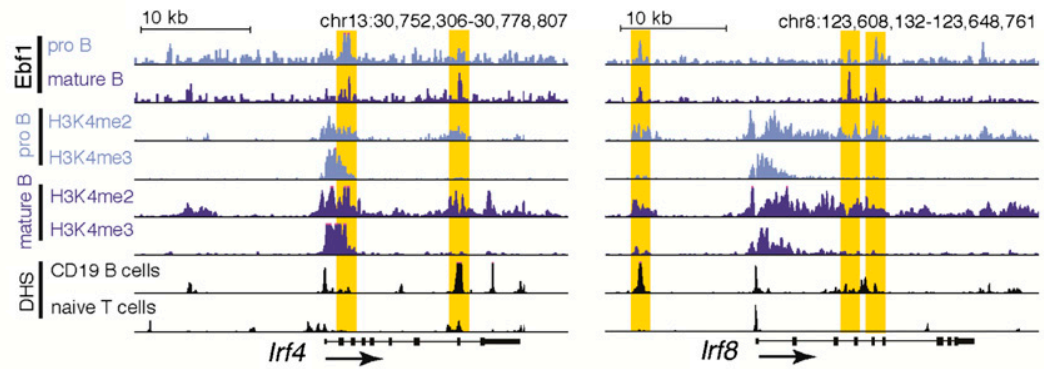

Figure 1. Impaired B lymphopoiesis and expression of regulatory genes in $E b f 1^{f l / f 1} R E R T^{C r e}$ bone marrow. $(A)$ Immunoblot analysis to detect Ebf1 and Stat5a in lysates of splenic B cells from mice that were treated with tamoxifen 4-OHT ( $3 \mathrm{mg}$ ) on two consecutive days and sacrificed on various days after first administration. $(B)$ Flow cytometric analysis of bone marrow to detect $\mathrm{B} 220^{+} \mathrm{CD} 43^{+}$pro-B cells, B220 ${ }^{\text {intermediate }} \mathrm{CD} 43^{-}$pre-B cells, and $\mathrm{B} 220^{\text {high }} \mathrm{CD} 43^{-}$recirculating B cells. Numbers in quadrants indicate percentage of cells. (C) Flow cytometric analysis to detect differentiation and generation of CD25 $5^{+} \kappa^{-}$pre-B cells and CD25 ${ }^{-} \kappa^{+}$immature B cells from $\mathrm{CD} 19^{+} \mathrm{CD} 43^{+} \mathrm{c}$-kit ${ }^{-}$pro-B cells in fetal liver cell cultures. Cells cultured in the presence of OP9 feeders and IL-7 were treated with $2 \mu \mathrm{M}$ 4-OHT for $24 \mathrm{~h}$ and cultured for an additional $4 \mathrm{~d}$. Differentiation was induced by withdrawal of IL-7. $(D)$ Semiquantitative RT-PCR analysis of $\kappa$ light chain GLTs in pro-B cells that were cultured in the presence of OP9 feeders and IL-7 for $6 \mathrm{~d}$ and treated with $2 \mu \mathrm{M}$ 4-OHT during the first day of culture. Data are representative of at least four $(A)$ or three $(B-D)$ experiments. (E) Quantitative RT-PCR analysis to examine the expression of B-cell-specific regulatory genes in pro-B-cell cultures. Data represent mean values of three independent biological replicates, and the raw cycle values were normalized to actin expression. Error bars indicate standard deviation (SD). (F) Quantification of Ebf1 binding to target genes in 38B9 cells by ChIP and quantitative PCR analysis. Binding is represented as percentage of input chromatin, and error bars represent SD of duplicate ChIP experiments (see also Supplemental Fig. S1; Supplemental Table S1). (G) Sequence tag profiles in pro-B cells and splenic B cells at the Irf4 and Irf8 loci. Regions of Ebf1 occupancy and H3K4me2 and H3K4me3 modifications in both pro-B cells (Lin et al. 2010) and splenic B cells (this study), as well as DNase I hypersensitivity sites (DHS) in CD19 ${ }^{+}$B cells and naive T cells (http://genome.ucsc.edu/ENCODE; Sabo et al. 2006), are shown. Tag density profiles are visualized using the University of California at Santa Cruz (UCSC) Genome Browser. Vertical yellow bars highlight genomic positions of Ebfl-binding sites that were identified by ChIP-seq analysis in pro-B cells (Lin et al. 2010; Treiber et al. 2010) and splenic B cells (this study).

Ebf1 has been implicated in the repression of alternative lineage determinants. In particular, the Id2 gene has been found to be repressed by Ebf1 (Pongubala et al. 2008; Thal et al. 2009|. Moreover, several genes that are expressed in natural killer (NK) cells are up-regulated in pro-B-cell Ebf1 ${ }^{+/-}$pro-B cells (Lukin et al. 2011). Therefore, we examined whether the conditional inactivation of $E b f 1$ in pro-B cells results in derepression of genes specifically expressed in myeloid cells, T cells, or NK cells. With the exception of Fcerl $\gamma$, no significant changes in myeloid gene expression were observed (Supplemental Fig. S2A; data not shown). Among the other genes examined, we only observed deregulation of Embigin and Flt3 (Supplemental Fig. S2A). These data indicate that the suppression of alternative lineage markers is generally maintained immediately after conditional inactivation of Ebf1. 
Unfortunately, the proliferation defect of Ebf1-deficient pro-B cells obscured an assessment of the maintenance of gene expression after multiple rounds of cell divisions.

Survival and proliferation defects of Ebf1-deficient pro- $B$ cells are rescued by forced Myb expression and $A-M u L V$ transformation, respectively

To examine the effects of Ebf1 inactivation on pro-B-cell survival, we determined the numbers of annexin V-positive and annexin V-negative cells between 2 and $6 \mathrm{~d}$ after tamoxifen-induced deletion of Ebf1 in vitro. Consistent with the decrease of $I L-7 R \alpha$ expression in Ebf1-deficient pro-B cells, the frequency of annexin/7-AAD-double-negative cells was markedly reduced (Fig. 2A). This defect was not overcome by the transgenic expression of $B c l 2$ or the transformation of mutant cells with $\mathrm{A}-\mathrm{MuLV}$, which overcomes the need of IL-7R signaling (Fig. 2B,C; Danial et al. 1995; Beck et al. 2009). Therefore, the cell death of Ebf1-deficient pro-B cells is not a consequence of only defective IL-7R signaling.
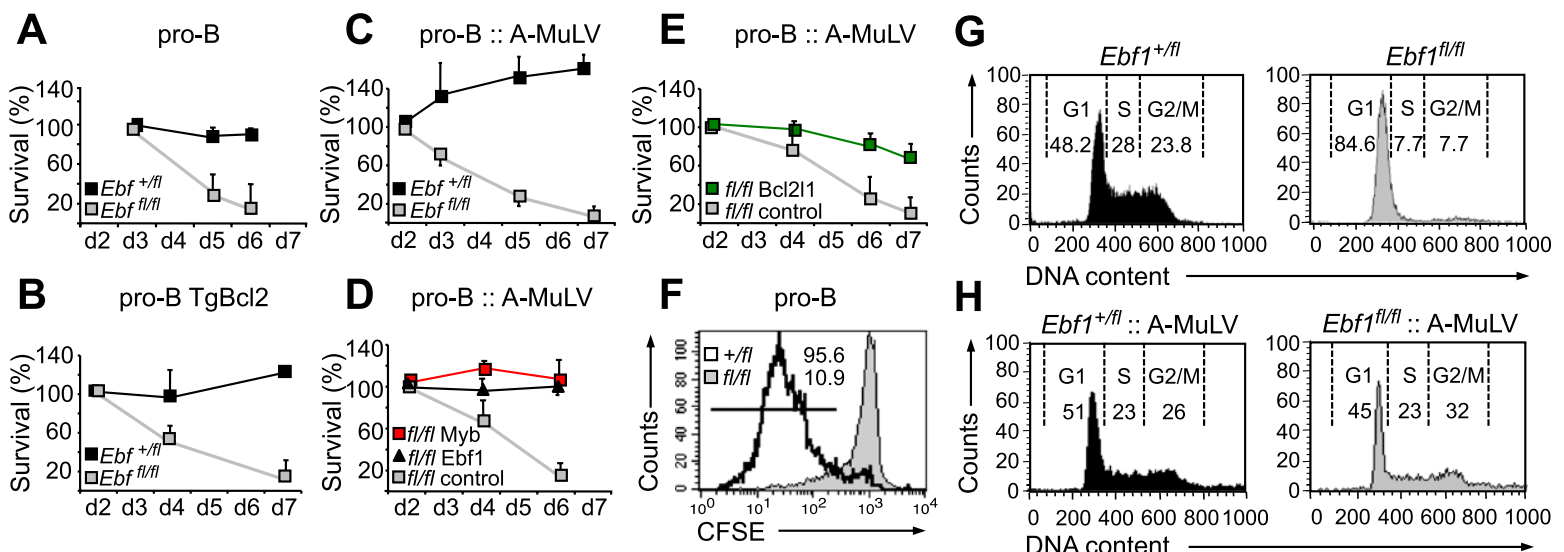

$\mathbf{H}$ DNA content
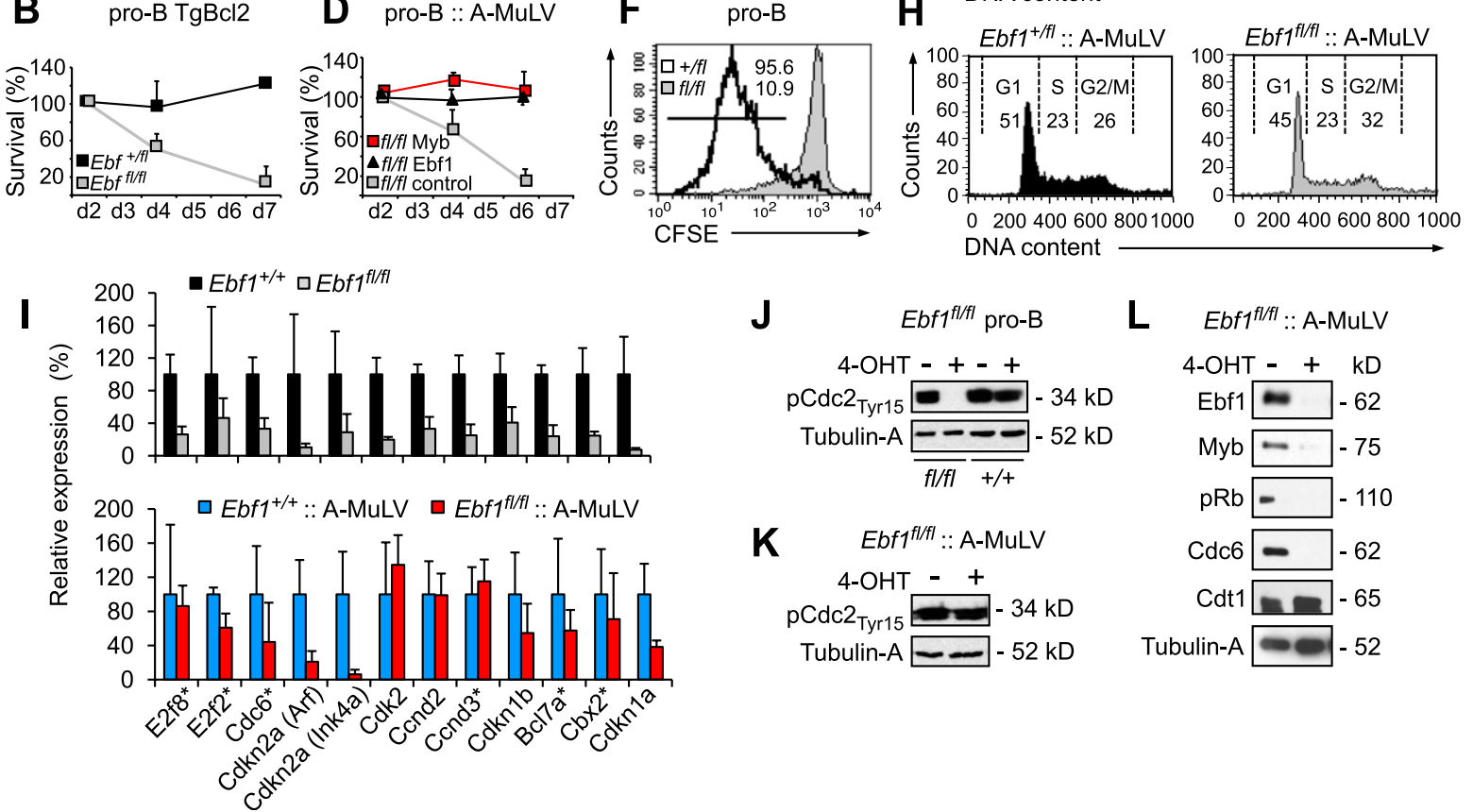

$\mathbf{J}$
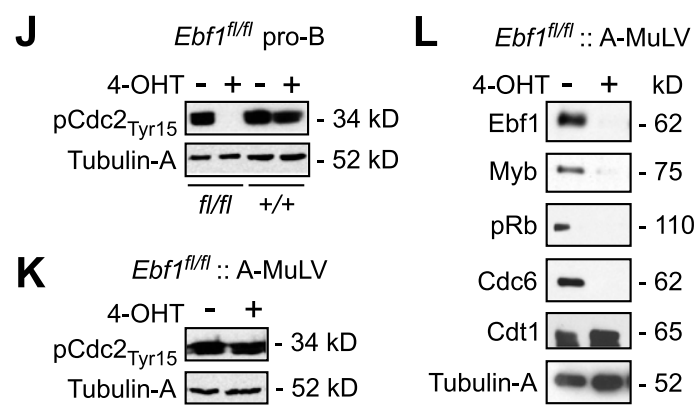

Figure 2. Ebf1 regulates proliferative expansion and survival of pro-B cells. $(A)$ Analysis of apoptosis of pro-B cells cultured in the presence of feeders and IL-7 after induced deletion of Ebf1. Numbers of viable (annexin V- and PI-negative) cells were determined by flow cytometry at the indicated time points after 4-OHT treatment, and the data were converted to the percentage of viable cells at day 3. Line graphs represent the average survival of three independent cell cultures at various days (d). (B,C) Analysis of survival of primary $E b f 1^{f l / f 1} R E R T^{C r e} T g B c l 2$ pro-B cells $(n=3)$ and transformed $E b f 1^{f l / f 1} R E R T^{C r e}:: \mathrm{A}-M u L V$ pro-B cells $(n=4)$, as described above. $(D, E)$ Analysis of apoptosis in A-MuLV-transformed $E b f 1^{f l / f 1}$ pro-B cells that have been transduced with a GFP-expressing retrovirus or bicistronic retroviruses expressing both GFP and various Ebf1 target genes. Cells sorted for GFP expression were treated with 4-OHT, and the percentages of viable cells were determined at the indicated time points after treatment $(n=4)$. Full and partial rescue of the survival defect of Ebf1-deficient cells is observed by expression of c-Myb and Bcl211, respectively. (F) Flow cytometric analysis of the proliferation of $E b f 1^{+/ f 1} R E R T^{C r e}$ (thick line) and $E b f 1^{f l / f 1} R E R T^{C r e}$ (gray fill) pro-B cells treated with $2 \mu \mathrm{M} 4-\mathrm{OHT}$ for $24 \mathrm{~h}$, cultured for $2 \mathrm{~d}$ without 4-OHT, labeled with CFSE, and assessed by CFSE dilution after $3 \mathrm{~d}(n=4)$. Numbers indicate the percentage of cells in the area marked by the thin bar. $(G, H)$ Flow cytometric analysis of cell cycle progression of $E b f 1^{+/ f 1} R E R T^{C r e}$ (black fill) and $E b f 1^{f l / f 1} R E R T^{C r e}$ (gray fill) primary pro-B $(G)$ or A-MuLV-transformed pro-B $(H)$ cell cultures $5 \mathrm{~d}$ after 4-OHT administration. Cells were fixed, stained with PI to assess DNA content, and gated for intact cells. Representative plot and quantitative analysis of cell cycle distribution are indicated $(n=3)$. Numbers indicate percentage of cells. $(I)$ Quantitative RT-PCR analysis to determine the expression of regulatory genes involved in cell cycle or survival and identified as indirect or direct $\left({ }^{*}\right)$ Ebf1 targets. Primary pro-B cells (top panel) and A-MuLVtransformed pro-B cells (bottom panel) were harvested $5 \mathrm{~d}$ after 4-OHT treatment. Data represent mean values of three biological replicates, and raw cycle values were normalized to actin. Ebf $1^{+/+}$samples were set to $100 \%$. (J,K) Immunoblot analysis to detect Cdc2 phosphorylation on Tyr 15 in primary $(J)$ and A-MuLV-transformed $(K) E b f 1^{f l / f 1} R E R T^{C r e}$ pro-B cells. $(L)$ Immunoblot analysis to detect Rb phosphorylation and expression of Ebf1, c-Myb, Cdc6, and Cdt1 in A-MuLV-transformed Ebf1 $1^{f l / f 1} R E R T^{C r e}$ pro-B cells. 
To attempt to rescue the survival defect of primary or A-MuLV-transformed $E b f 1^{f l / f 1}$ pro-B cells, we transduced mutant cells with a GFP-expressing control retrovirus or bicistronic retroviruses expressing both GFP and various Ebf1-regulated target genes. Expression of IL-7R $\alpha$ or a constitutive active form of Stat5 failed to overcome the survival defect of primary and transformed Ebf1 $1^{f l / f l}$ pro-B cells (Supplemental Fig. S2B; data not shown). Myb rescued the survival defect of transformed $E b f 1^{f l / f 1}$ pro-B cells as efficiently as Ebf1, although Myb was not sufficient to allow for survival of primary Ebf1 $1^{f l / f l}$ pro-B cells (Fig. 2D; Supplemental Fig. S2B). We also observed a partial rescue of transformed Ebf1 ${ }^{f 1 / f 1}$ pro-B cells with Bcl2l1 (Fig. 2E), consistent with its role in B-cell survival (Grillot et al. 1996; Cheng et al. 2003). Despite its implied role in pro-Bcell survival, the Ebf1 target Foxo1 did not rescue the survival defect of transformed $E b f 1^{f l / f l}$ pro-B cells (Supplemental Fig. S2C). Quantitative RT-PCR analysis indicated that forced $\mathrm{Myb}$ expression restored the expression of Bc1211, Foxo1, and Ikzf1, but did not rescue the impaired expression of $I L-7 R \alpha$ and $I g l 11$ ( $\lambda 5$ ) (Supplemental Fig. S2D). Thus, Myb acts downstream from Ebf1 to regulate the survival of pro-B cells and the expression of $B c 1211$, but is not sufficient to overcome the requirement for Ebfl function in cell cycle progression.

We also determined the effects of Ebf 1 deletion on cell proliferation and cell cycle progression by performing flow cytometric analysis of cells labeled with CFSE or PI. Ebf1 $1^{f l / f 1}$ pro-B cells showed marked proliferation and cell cycle defects (Fig. 2F,G). In contrast to the survival defect, the cell cycle defect of primary Ebf1-deficient pro-B cells, which accumulate in the G1 phase, was overcome by transformation with A-MuLV (Fig. 2H). Thus, Ebf1 regulates proliferation and survival of pro-B cells by distinct mechanisms.

Cell cycle progression is regulated by cyclins, cyclindependent kinases (CDKs), retinoblastoma proteins, and CDK inhibitors. In particular, D-type and E-type cyclins regulate G1-phase progression and G1/S transition, respectively. D-type cyclins integrate extracellular signals to G1-phase progression, and complexes of Cdk4/5 and $\mathrm{D}$-cyclins enhance $\mathrm{Rb}$ phosphorylation, resulting in activation of E2F transcription factors. Several of these genes are directly or indirectly regulated by Ebf1 (Supplemental Table S1; Lin et al. 2010; Treiber et al. 2010). By quantitative RT-PCR analysis of primary Ebf1-deficient pro-B cells, we confirmed marked changes in the expression of direct Ebf1 targets implicated in cell cycle progression (Fig. 2I). These genes include E2f2, E2f8, Cdk2, cyclin D2 (Ccnd2), and cyclin D3 (Ccnd3), as well as Cdc6, an essential regulator of the initiation of DNA replication that is also under the control of E2Fs. In addition, the expression of the prosurvival gene Bcl211, but not that of Bcl2a1 and Mcl1, was altered in primary and transformed Ebf1-deficient pro-B cells (Fig. 1E; Supplemental Fig. S2D; data not shown). A-MuLV-mediated transformation targets the expression of both D-type cyclins and E2Fs (Coutts et al. 2000; Parada et al. 2001). In A-MuLV-transformed $E b f 1^{f l / f 1}$ pro-B cells, E2f8, Ccnd2, and Ccnd3 were expressed at similar levels in $E b f 1^{f l / f 1}$ and $E b f 1^{+/ f 1}$ pro-B cells (Fig. 2I), suggesting that $\mathrm{v}$-Abl compensates for the function of Ebf1 in the regulation of these genes and allows for cell cycle progression in the absence of Ebf1.

In primary Ebf1-deficient pro-B cells, we also detected a decrease in Ccnd3 RNA and protein expression (Fig. 2I; Supplemental Fig. S2E). However, we could not rescue the cell cycle defect by forced expression of Ccnd3 (Supplemental Fig. S2F,G). Primary Ebf1-deficient pro-B cells also showed impaired expression of $\mathrm{Cdk} 2$ and the absence of phosphorylation of Cdc2 (Cdk1) (Fig. 2I,J). Phosphorylation of Cdc2 and expression of Cdk2 were restored in transformed Ebf1-deficient pro-B cells, whereas the phosphorylation of $\mathrm{Rb}$ and the expression of $C d c 6$ remained low (Fig. $2 \mathrm{~K}, \mathrm{~L})$. This observation raises the possibility that an origin activation checkpoint is bypassed in transformed Ebf1deficient pro-B cells, allowing them to proceed into an abortive $S$ phase, followed by apoptosis (Tudzarova et al. 2010).

\section{Ebf1 regulates generation of $B 1$ and marginal zone (MZ) B cells as well as BAFF-R-mediated \\ $B$-cell survival}

To gain insight into the role of Ebf1 in peripheral B cells, we analyzed splenic B cells in tamoxifen-treated $E b f 1^{f l / f 1}$ $R E R T^{\text {Cre }}$ mice, as well as in $E b f 1^{f l / f l} C d 21^{C r e}$ and $E b f 1^{f l / f 1}$ Cd19 ${ }^{\text {Cre }}$ mice, which delete the floxed genes in transitional and mature B cells (Rickert et al. 1997; Kraus et al. 2004). In tamoxifen-treated $E b f 1^{f l / f 1} R E R T^{C r e}$ mice, the frequencies and numbers of $\mathrm{CD} 19^{+}$splenic B cells were similar to those found in $E b f 1^{+/ f l} R E R T^{C r e}$ mice (Supplemental Fig. S3A,B). However, homozygous mutant mice had markedly reduced frequencies of transitional $B$ cells $\left(\mathrm{B} 220^{+} \mathrm{AA} 4.1^{+}\right)$, immature B cells, and MZ B cells $\left(\mathrm{CD} 21^{+} \mathrm{CD} 23^{-}\right)$(Fig. 3A). In these mutant mice, follicular

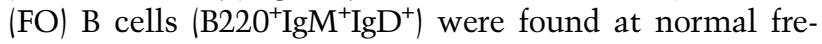
quencies but showed reduced surface expression of CD21 (Fig. 3A).

In $E b f 1^{f l / f 1} C d 21^{C r e}$ and $E b f 1^{f l / f 1} C d 19^{C r e}$ mice, MZ B cells were also diminished (Fig. 3B; Supplemental Fig. S3C-E). Moreover, FO B cells showed a reduced surface expression of CD21 and CD19 (Fig. 3B; Supplemental Fig. S3E,F). Thus, the entire CD19/CD21 coreceptor complex is affected by the inactivation of Ebf1. In residual MZ B cells and in FO B cells that express CD21 at a high level, we detected abundant unrecombined $E b f 1^{f 1}$ alleles or expression of Ebf1 (Supplemental Fig. S3E,G). In contrast, very few unrecombined $E b f 1^{f l}$ alleles were found in the corresponding $E b f 1^{+/ f 1}$ cell populations. These findings suggest that $M Z B$ cells with recombined $E b f 1^{f l / f l}$ alleles have been depleted and replaced by cells that have escaped inactivation of $E b f 1$.

Analysis of peritoneal B cells in $E b f 1^{f l / f 1} R E R T^{C r e}$ and Ebf $1^{f l / f 1} C d 21^{C r e}$ mice revealed an almost complete loss of B1 cells (Supplemental Fig. S3H,I; data not shown). Thus, Ebf1 is required for the generation and/or maintenance of transitional and MZ B cells in the spleen and B1 cells in the peritoneum, but is dispensable for the maintenance of resting FO B cells.

By quantitative RT-PCR analysis of $E b f 1^{f l / f 1} R E R T^{\text {Cre }}$ $\mathrm{MZ} \mathrm{B}$ cells, sorted $6 \mathrm{~d}$ after tamoxifen treatment to 

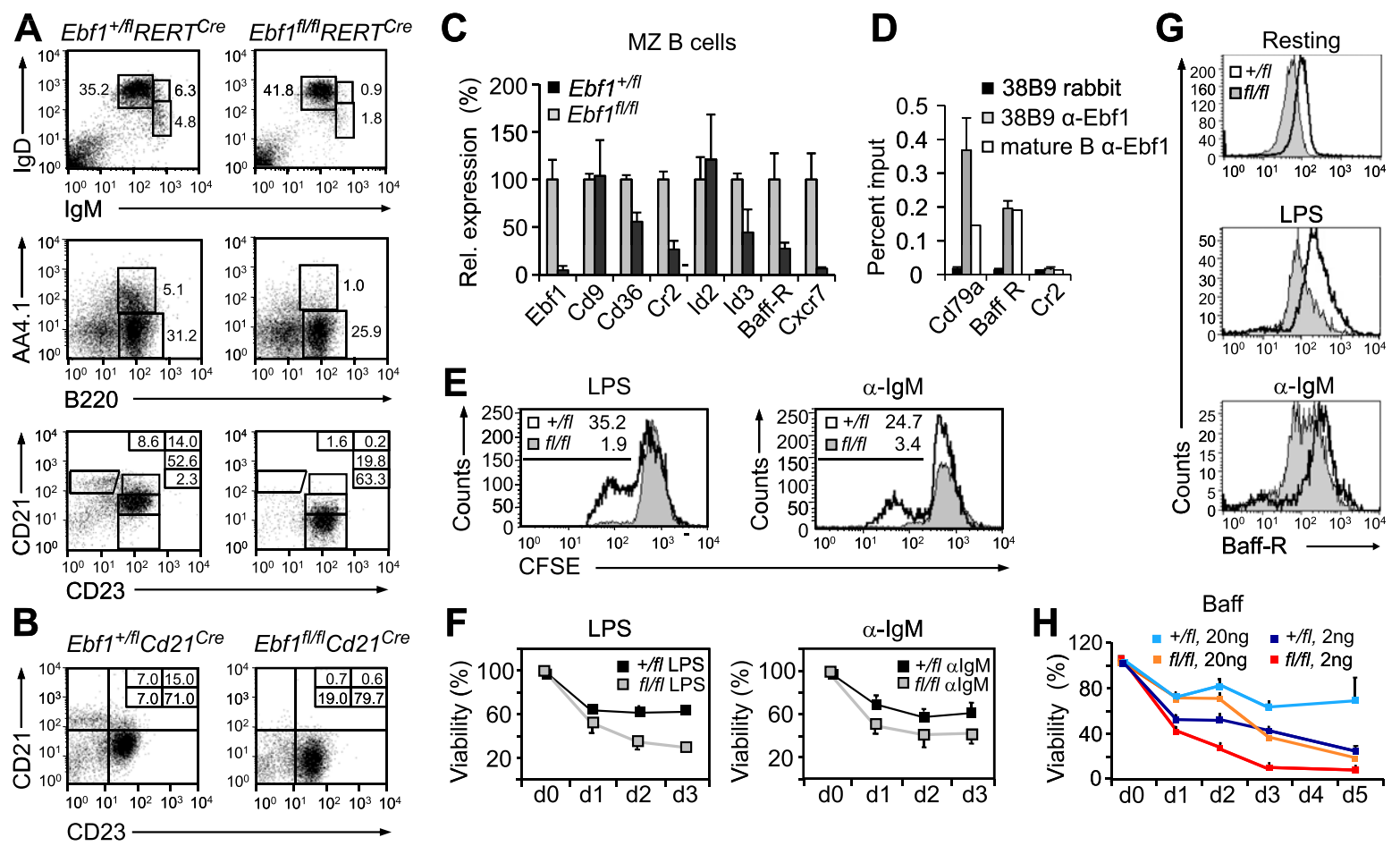

Figure 3. Roles of Ebf1 in peripheral B-cell subsets and BAFF-R-mediated cell survival. (A) Flow cytometric analysis of $E b f 1^{+/ f 1} R E R T^{C r e}$

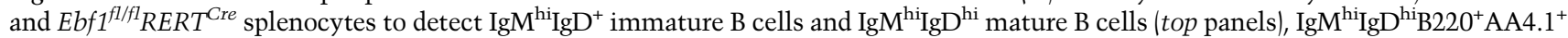
transitional B cells (middle panels), and B220 ${ }^{+} \mathrm{CD} 23^{-} \mathrm{Cd} 21^{\mathrm{hi}} \mathrm{MZ} \mathrm{B}$ cells and B220 $0^{+} \mathrm{CD} 23^{+} \mathrm{CD} 21^{+}$FO B cells (bottom panels). Numbers in quadrants indicate percentage of cells. (B) Flow cytometric analysis of $E b f 1^{+/ f l} C d 21^{\text {Cre }}$ and $E b f 1^{f l / f l} C d 21^{\text {Cre }}$ splenocytes to detect MZ B cells and FO B cells. $(C)$ Quantitative RT-PCR analysis of Ebf1-regulated targets in sorted MZ B cells. Fold expression values are relative to heterozygote control cells. (D) ChIP analysis to examine binding of Ebf1 to the Tnfrsf13c (Baff-R) locus in 38B9 pro-B cells or MACSenriched splenic B cells. Binding is represented as percentage of input chromatin. (E) Flow cytometric analysis of proliferation of splenic B cells that were depleted of non-FO B cells with antibodies directed against CD43, CD4, CD8a, Gr1, AA4.1, and CD9. Cells sorted 10 d after the initial 4-OHT treatment were CFSE-labeled and stimulated with LPS or $\alpha \operatorname{IgM~} \mathrm{F}\left(\mathrm{ab}^{\prime}\right)_{2}$. Proliferation was determined by CFSE dilution $3 \mathrm{~d}$ after stimulation. Numbers indicate percentages of cells in the area marked by the thin bar. (F) Analysis of apoptosis of LPS- or $\alpha$-IgM-stimulated splenic B cells at the specified days (d) $(n=3)$. $(G)$ Flow cytometric analysis of surface expression of BAFF-R in resting and stimulated splenic B cells. Cells were activated with the indicated stimuli for $40 \mathrm{~h}$. The graph is representative of three experiments. (H) Analysis of the survival of $E b f 1^{+/ f 1} R E R T^{C r e}$ and $E b f 1^{f l / f 1} R E R T^{C r e}$ resting splenic B cells in the presence of optimal $(20 \mathrm{ng} / \mathrm{mL})$ and limiting $(2 \mathrm{ng} / \mathrm{mL})$ exogenous BAFF $(n=3)$.

minimize the appearance of cells with nondeleted alleles, we found reduced expression of $I d 3$ and $C x c r 7$, which regulate the generation and maintenance of $\mathrm{MZ} \mathrm{B}$ cells, respectively (Fig. 3C; Quong et al. 2004; Wang et al. 2012). In Ebf1-deficient MZ B cells, we also observed reduced expression of Baff-R (Tnfrsf13c) and Cr2 (Cd21). ChIP analysis to detect binding of Ebf1 to these gene loci indicated that Baff- $\mathrm{R}$ is a direct target of Ebf1 in both pro-B and mature B cells (Fig. 3D).

Stimulation of sorted resting B cells from $E b f 1^{f l / f l} R E R T^{\text {Cre }}$ and $E b f 1^{+f l} R E R T^{\text {Cre }}$ mice by LPS, CpG, or anti-IgM indicated that proliferation of activated $E b f 1^{f l / f l}$ cells, as determined by flow cytometric tracing of CFSE, was markedly impaired relative to $E b f 1^{+/ f l}$ cells (Fig. 3E; Supplemental Fig. S4A). Moreover, the frequencies of cells in S phase of the cell cycle, measured by incorporation of EDU, were lower in $E b f 1^{f l / f l}$ cells as compared with $E b f 1^{+/ f l}$ cells (Supplemental Fig. S4B). To determine whether the pronounced proliferation defect of LPS-stimulated Ebf1 $1^{f l / f l}$ cells includes a signaling defect, we examined the nuclear translocation of NF-кB. The nuclear accumulation of c-Rel and p65 was similar with LPS-stimulated $E b f 1^{f l / f l}$ and $E b f 1^{+/ f 1}$ cells, suggesting that the defect does not involve impaired signaling (Supplemental Fig. S4C).

We also determined the survival of stimulated $E b f 1^{f l / f 1}$ $R E R T^{C r e}$ and $E b f 1^{+/ f l} R E R T^{C r e}$ splenic B cells in vitro and found a decrease in the survival of $E b f 1^{f l / f l} \mathrm{~B}$ cells, irrespective of the mode of stimulation (Fig. 3F; Supplemental Fig. S4D). Survival of mature B cells depends on two signaling determinants, BCR and BAFF-R, which monitor the presence of antigen and neighboring cells, respectively (Mecklenbrauker et al. 2004; Beck et al. 2009; Srinivasan et al. 2009). Analysis of the surface expression of BAFF-R by flow cytometry revealed a reduction in resting and stimulated $E b f 1^{f l / f l} \mathrm{~B}$ cells, whereby the defect was more pronounced in stimulated cells (Fig. 3G). To further examine the requirement of Ebfl for BAFF-mediated B-cell survival, we determined the effects of exogenous BAFF ligand in unstimulated in vitro cultures. Addition of BAFF rescued, at least in part, the survival defect of $E b f 1^{f l / f l}$ splenic B cells in a dose-dependent manner (Fig. $3 \mathrm{H}$ ). However, we did not observe an enhanced rescue of the 
survival defect by combining either BAFF with LPS or IL10 and IL6, or anti-IgM with anti-CD40 treatment (data not shown).

\section{Impaired BCR and Akt signaling in Ebf1-deficient B cells}

The BCR activates several signaling pathways, whereby the BCR-mediated survival signal is governed by PI3K/ Akt signaling (Srinivasan et al. 2009; Okkenhaug and Fruman 2010; Werner et al. 2010). Ebf1 regulates multiple components of BCR signaling pathways, including $C d 79 a$ $(\operatorname{Ig} \alpha), C d 79 b(\operatorname{Ig} \beta)$, and $C d 19$. In anti-IgM-stimulated Ebf $1^{f l / f 1} \mathrm{~B}$ cells, tyrosine phosphorylation of a subset of proteins, including proteins migrating at $\sim 75$ and $\sim 37$ $\mathrm{kDa}$, is impaired (Fig. 4A). In particular, we observed reduced phosphorylation of CD79a, despite normal CD79a protein expression (Fig. 4B). Moreover, phosphorylation of CD19, a BCR-proximal process, was reduced in anti-IgMstimulated $E b f^{f l / f l}$ B cells (Fig. 4C). Consistent with the phosphorylation defects, $\mathrm{Ca}^{2+}$ mobilization in response to anti-IgM stimulation was also impaired in $E b f 1^{f l / f l} \mathrm{~B}$ cells (Fig. 4D). We also examined the PI3K arm of BCR by analyzing the phosphorylation of Akt/PKB. BCR-stimulated phosphorylation of Akt was markedly reduced (Fig. $4 \mathrm{C})$, suggesting that Ebf1 regulates both canonical and Akt-mediated BCR signaling. In resting Ebf1-deficient B cells, we did not detect an altered expression of genes that are regulated by tonic Akt signaling (Supplemental Fig. S4E; Srinivasan et al. 2009), suggesting that Ebf1 is re-
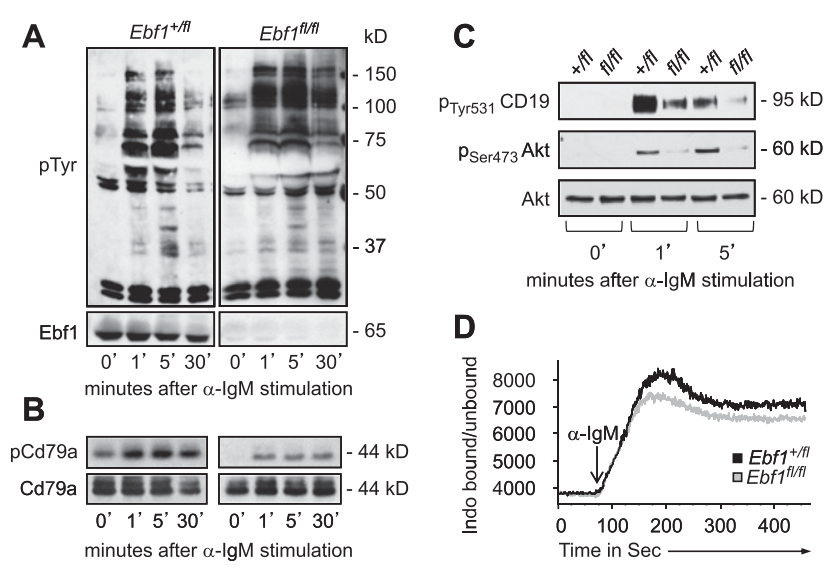

Figure 4. Role of Ebf1 in BCR and Akt signaling. (A) Immunoblot analysis of tyrosine phosphorylation in MACS-purified and $\alpha \operatorname{IgM~} \mathrm{F}\left(\mathrm{ab}^{\prime}\right)_{2}$-stimulated $E b f 1^{+/ f 1} R E R T^{C r e}$ and $E b f 1^{f l / f 1} R E R T^{C r e}$ splenic $B$ cells in vitro. Efficient deletion of Ebfl is shown in the bottom panel. (B) Immunoblot analysis of anti-CD79aimmunoprecipitated protein to detect phosphorylated and total CD79a protein. (C) Immunoblot analysis of phosphorylated CD19 (pCD19) (top panel) and Akt (middle panel) in FACSpurified splenic B cells stimulated with $\alpha \operatorname{IgM~} F\left(\mathrm{ab}^{\prime}\right)_{2}$ for the indicated times. Blots are representative of three independent experiments. $(D)$ Analysis of experimentally induced $\mathrm{Ca}^{2+}$ fluxes in resting mature $\mathrm{B}$ cells of $E b f 1^{+/ f 1}$ and $E b f 1^{f l / f 1} R E R T^{C r e}$ mice. Indo-1AM-loaded cells were stimulated with $\alpha \operatorname{IgM~} \mathrm{F}\left(\mathrm{ab}^{\prime}\right)_{2}$, and free intracellular $\mathrm{Ca}^{2+}$ was measured in real time. Data are representative of six independent experiments. quired for stimulated but not tonic BCR-mediated Akt signaling.

\section{Analysis of Ebf1 targets in mature B cells by RNA expression and ChIP-seq analyses}

Microarray analysis of resting splenic B cells of $E b f 1^{+/ f l}$ $R E R T^{C r e}$ and $E b f 1^{f l / f 1} R E R T^{C r e}$ mice revealed differences in the expression of multiple cell cycle- and signaling-related genes (Supplemental Fig. S5A,B). Of $\sim 200$ genes that showed threefold or higher differences in expression, $80 \%$ and $20 \%$ were down-regulated and up-regulated in $E b f 1^{f l / f 1}$ cells, respectively. Among the Ebf1-activated genes, we identified several genes related to cell cycle control, such as Mcm10, Bub1, and E2f8, as well as genes regulating BCR/Akt signaling, including Cr2, Dok3, and Hck. However, we detected no significant changes in the expression of known Ebf1 target genes, like Cd79a, Pax5, and Blnk (data not shown).

Many putative Ebf1 target genes differed from the target genes previously identified in our microarray and ChIP-seq analyses of pro-B cells (Treiber et al. 2010). To identify Ebf1-bound genes in mature splenic B cells, we performed a ChIP-seq analysis. In total, we identified 7424 significant Ebf1 peaks by comparing Ebf1 and control data sets using the CCAT peak-calling algorithm (Treiber et al. 2010). Assigning the Ebf1-binding sites to genes within $100 \mathrm{~kb}$ of the transcription start sites (TSSs), we found 4825 genes that are putatively bound by Ebf1 in mature B cells (Supplemental Table S2). To assess the quality of the ChIPseq data, we performed quantitative ChIP experiments on 46 randomly chosen ChIP-seq peaks and could validate 15 of the peaks, which correspond to a greater than eightfold enrichment of Ebf1 tags (Supplemental Table S3). For further analysis, we used the top $25 \%$ of the peaks (1528 genes), corresponding to the eightfold enrichment. We also compared the data sets with our previous data sets of Ebf1 binding in pro-B cells. We found that $\sim 30 \%$ of genes bound in pro-B cells overlapped with those bound in mature $\mathrm{B}$ cells (Fig. 5A, left panel). Using the top $25 \%$ of the pro-Bcell library, this fraction of overlapping sites increased to $\sim 44 \%$. Conversely, $\sim 58 \%$ of genes bound in mature B cells overlapped with those bound in pro-B cells when the top $25 \%$ of the mature B-cell library were used for comparison (Fig. 5A, right panel). This analysis also showed that the distribution of Ebf1-binding sites is altered in mature B cells and includes significantly more binding sites in promoter-proximal regions (Fig. 5B). Bioinformatic analysis of Ebf1-binding regions to detect overrepresented transcription factor-binding sites identified different motifs than those found in pro-B cells. In mature B cells, Sp1 and E2F transcription factor-binding motifs were overrepresented in Ebf1-bound regions (Supplemental Table S4).

Previous analysis of Ebf1 binding in pro-B cells revealed a good correlation of Ebf1 binding and H3K4me2 modifications (Treiber et al. 2010). By ChIP-seq analysis of H3K4me2 and H3K4me3 modifications, we also observed this correlation in mature B cells, although in some genes with Ebf1 binding only in mature B cells, such as Pkib, 
A

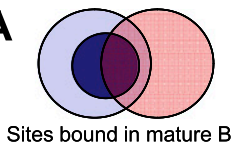

all $\square$ Shared: $29.6 \%$

top $25 \% \square$ Shared: $43.8 \%$

C
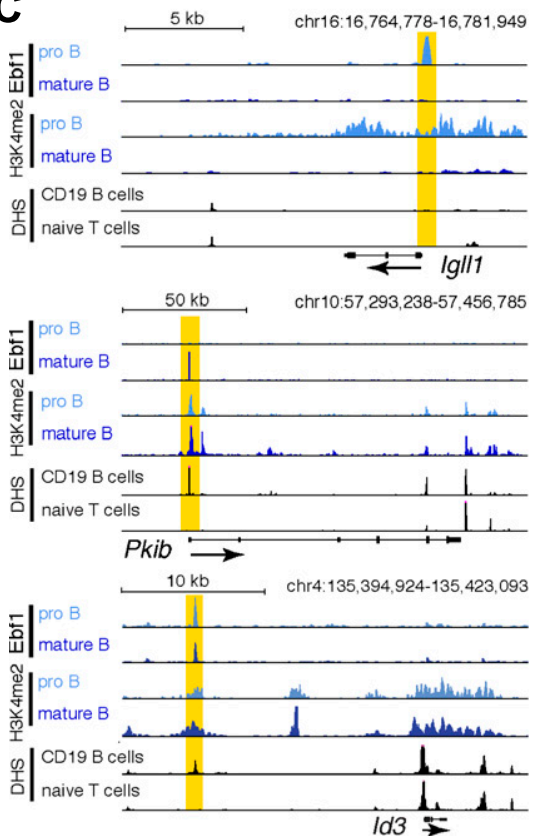

B

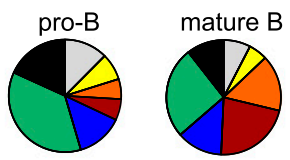

D
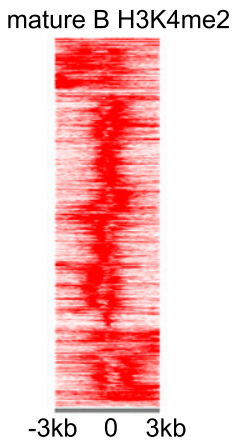

Distance from Ebf1-binding sites

G

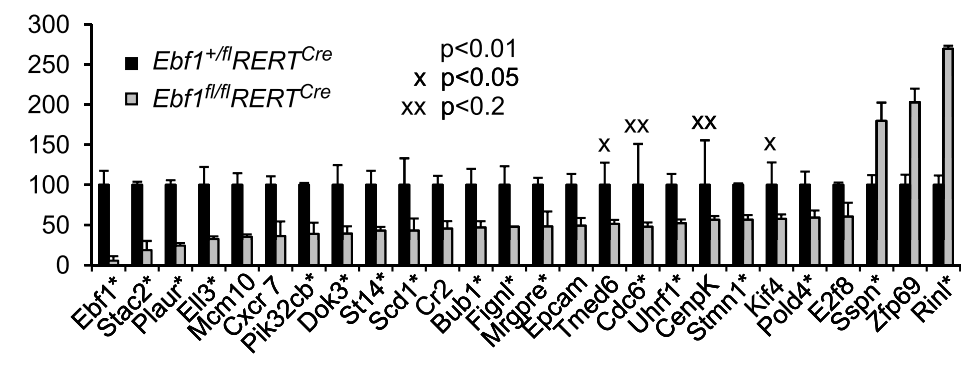

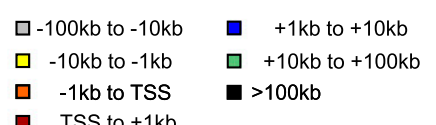

TSS to $+1 \mathrm{~kb}$

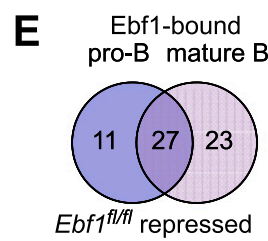

Ebf1-bound

pro-B mature $\mathrm{B}$

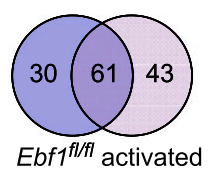

$\mathbf{F}$

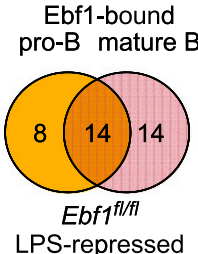

Ebf1-bound pro-B mature $B$

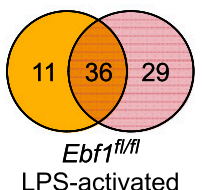

Figure 5. Analysis of Ebf1 binding and Ebf1-mediated gene expression in mature B cells. (A) Overlap of genes occupied by Ebf1 in splenic B cells, as determined by ChIP-seq analysis, with Ebf1-bound genes in pro-B cells (Treiber et al. 2010). Shades of blue and red represent genes bound in pro-B cells and mature B cells, respectively. Dark colors represent Ebf 1 targets in the top $25 \%$ of either library (see Supplemental Table S1). (B) Distribution of Ebf1-bound regions relative to annotated gene loci in mature B cells and pro-B cells. (C) Association of Ebf1-bound regions with H3K4me2 modification and DHS in Igll1, Pkib, and Id3 as representatives for genes bound by Ebfl at different stages of differentiation. UCSC Genome Browser was used to visualize binding patterns. DHS data were obtained from ENCODE (http://genome.ucsc.edu/ENCODE). Vertical yellow band pattern indicates the position of Ebf1-binding sites. (D) Correlation of Ebf1 occupancy and H3K4me2 patterns in mature B cells. The heat map reflects the enrichment of H3K4 dimethylation in the vicinity of the top $25 \%$ Ebf1 peaks in mature B cells. The center of the Ebf1-binding sites in mature B cells is represented by $0 .(E, F)$ Overlap of Ebf1-bound genes in pro-B cells and mature B cells $(<100 \mathrm{~kb}$ from the TSS) that were also identified as functional targets by lossof-function microarray analyses in unstimulated B cells $(E)$ and LPS-stimulated B cells $(F)$. The numbers represent Ebf1-bound genes that were identified as genes differentially expressed in $E b f 1^{f l / f 1} R E R T^{\text {Cre }}$ versus $E b f 1^{+/ f 1} R E R T^{C r e} \mathrm{~B}$ cells. The identity of the genes and positions of the binding sites are shown in Supplemental Tables S5-S8. $(G)$ Quantitative RT-PCR analysis of Ebf1-regulated targets that were identified in the microarray analysis. A representative set of 26 genes of the top 200 Ebfl-regulated target genes is shown, and fold expression values are relative to heterozygote control cells. Ebfl-bound genes among these targets are marked by an asterisk (see also Supplemental Fig. S3; Supplemental Tables S5, S6).

H3K4me2 modifications can already be detected in pro-B cells (Fig. 5C,D).

Matching the data of the microarray analysis of resting splenic B cells of $E b f 1^{f l / f 1}$ mice with the ChIP-seq data set indicated that 104 of the Ebf1-occupied genes were downregulated and 50 were up-regulated relative to $E b f 1^{+/ f l} \mathrm{~B}$ cells (Fig. 5E; Supplemental Tables S5, S6). We also examined the effects of Ebf1 deletion on gene expression in LPS-stimulated B cells. Microarray analysis indicated that a relatively small subset of LPS-regulated genes is dependent on Ebf1, consistent with our finding that NF-кBmediated gene induction is not impaired in $E b f 1^{f l / f l} \mathrm{~B}$ cells (Fig. 5F; Supplemental Fig. S6; Supplemental Tables S7, S8). Virtually all of the functional Ebf1 targets that were confirmed by quantitative RT-PCR were also identified in the ChIP-seq analysis, suggesting that Ebf1 may directly regulate these genes (Fig. 5G; Supplemental Table S2).

\section{Impaired GC formation in the absence of Ebf1}

Activation of splenic B cells by antigen encounter results in the generation of GC B cells that undergo class switch recombination and somatic hypermutation (Klein and Dalla-Favera 2008). To assess the role of Ebf1 in GC formation, we treated $E b f 1^{f l / f l} R E R T^{C r e}$ mice with tamoxifen in vivo and subsequently immunized the mice with sheep red blood cells (SRBCs). Seven days after immunization, the number of splenic GC B cells $\left(B 220^{+} \mathrm{PNA}^{+} \mathrm{FAS}^{\text {hi }}\right)$ 
A

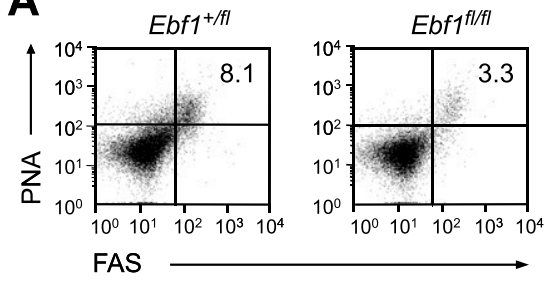

B
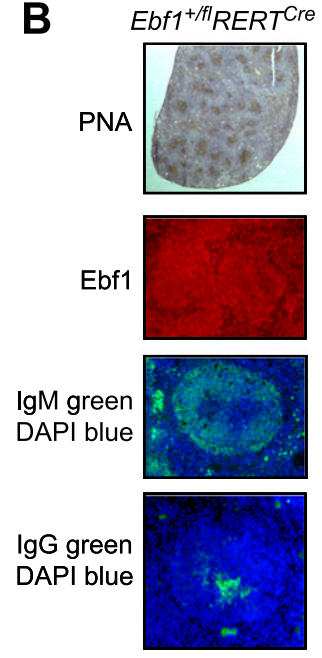
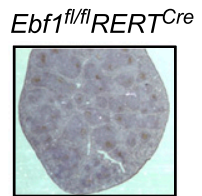

D
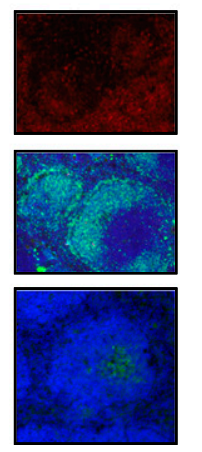

$\mathbf{E}$
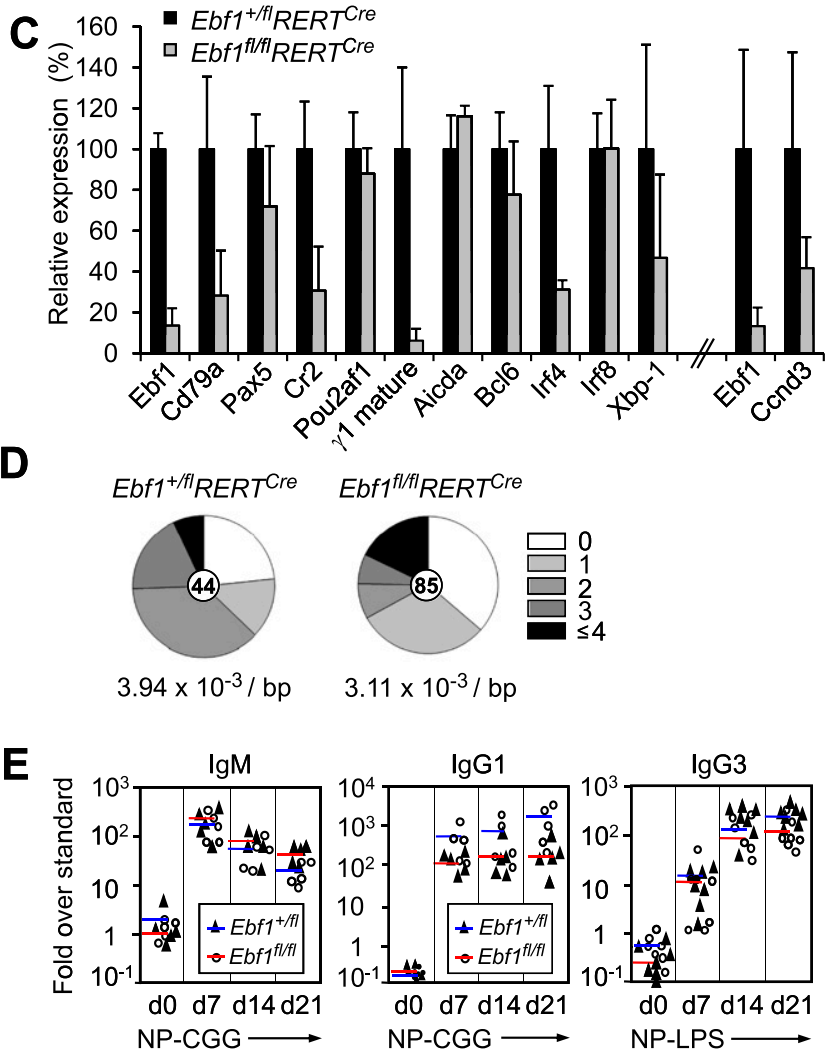

Figure 6. Impaired GC development in the spleens of $E b f 1^{f l / f l} R E R T^{C r e}$ mice. $(A)$ Flow cytometric analysis to detect GC B cells in the spleens of SRBC-immunized $E b f 1^{f l / f 1} R E R T^{C r e}$ and $E b f 1^{+/ f 1} R E R T^{C r e}$ mice. Mice were immunized $8 \mathrm{~d}$ after the first 4-OHT treatment and were analyzed $6 \mathrm{~d}$ after immunization. Samples were gated on living B220 cells, and the numbers on the FACS plots represent the percentage of $\mathrm{PNA}^{+} \mathrm{FAS}^{\mathrm{hi}} \mathrm{GC}$ B cells $(n=6)$. (B) Analysis of immune responses of $E b f 1^{f l / f 1} R E R T^{\text {Cre }}$ mice. Spleen sections were stained with PNA (top panel) to reveal GC cells, and with antibodies to IgM (green) to reveal B-cell follicles and total IgG (green, bottom panel). Nuclei were stained with DAPI. $(C)$ Gene expression analysis of sorted PNA ${ }^{+}$FAS ${ }^{\text {hi }}$ GC B cells of the indicated genotypes by quantitative RT-PCR. Black and gray bars represent the averages of individually sorted samples $(n=3)$. $(D)$ Normal somatic hypermutation of $E b f 1^{f l / f l} R E R T^{C r e}$ GC B cells upon immunization with SRBCs. Mice were immunized as described in $A$; genomic DNA was extracted from sorted GC B cells and subjected to nested PCR amplification with two degenerate V and J segment primer pairs, and the amplified products corresponding to $\mathrm{J}_{\mathrm{H}} 3$ were separated and cloned. The number of clones sequenced is shown in the circles in the middle of the pie diagrams; each diagram is representative of two independent experiments, with at least 40 cloned sequences each. (E) Relative titers of immunoglobulin subtypes in sera of $E b f 1^{+/ f l} R E R T^{C r e}$ mice (black triangles and blue lines represent individual samples and averages, respectively) and $E b f 1^{f l / f 1} R E R T^{C r e}$ mice (open circles and red lines represent individual samples and averages, respectively) at the specified days (d), determined by ELISA.

was not significantly elevated above basal levels in $E b f 1^{f l / f l}$ $R E R T^{C r e}$ mice in contrast to $E b f 1^{+/ f l} R E R T^{C r e}$ mice (Fig. 6A). We also detected impaired proliferation of Ebf1deficient GC B cells, as determined by BrDU incorporation in vivo (Supplemental Fig. S7A). Twelve days after immunization, however, the reduction of the number of GC B cells in $E b f 1^{f l / f l} R E R T^{\text {Cre }}$ mice was less severe, which could be accounted for by the accumulation of cells with nonrecombined $E b f 1^{f l / f l}$ alleles (Supplemental Fig. S7B). A progressive loss of Ebf1-deficient GC B cells was also inferred from the analysis of $E b f 1^{f l / f l} C \gamma 1^{C r e}$ mice. In these mice, Cre recombinase is induced specifically in GC B cells by transcription of the Ig $\gamma 1$ constant region gene segment $4 \mathrm{~d}$ after immunization with T-cell-dependent (TD) antigens (Casola et al. 2006). In immunized Ebf1 $1^{f l / f l}$ $C \gamma 1^{C r e}$ mice, we detected two to three times fewer GC $B$ cells by flow cytometry, and the frequency of non- recombined Ebf1 $1^{f l / f 1}$ alleles increased between 7 and $12 \mathrm{~d}$ after immunization, consistent with a requirement for Ebf1 in the maintenance of GC B cells (Supplemental Fig. S7C).

To gain insight into the defect of Ebf1-deficient GC B cells, we immunized $E b f 1^{+/ f l}$ and $E b f 1^{f l / f l} R E R T^{C r e}$ mice with SRBCs and analyzed the spleen by immunohistochemistry $7 \mathrm{~d}$ after immunization. In $E b f 1^{f l / f l}$ spleens, we detected a significant decrease in the size of PNA-positive GCs and in the staining for IgG-positive cells (Fig. 6B). However, the staining for IgM was similar in $E b f 1^{f l f l}$ and $E b f 1^{+/ f l}$ spleens. Quantitative RT-PCR analysis of genes characteristic of GC B cells revealed down-regulation of Cr2, IgC $r 1$, and $I r f 4$ in Ebf1 $1^{f l / f l}$ GC B cells (Fig. 6C). Cr2, encoding $\mathrm{CD} 21$, has been implicated in the maintenance of GCs (Fischer et al. 1998; Srinivasan et al. 2009), and Irf4 is a key transcription factor for GC B-cell formation 
(Klein and Dalla-Favera 2008). In ChIP-seq and ChIP analyses, we detected binding of Ebf1 to an intronic DNase hypersensitivity site (DHS) of Irf4 in mature B cells but not in pro-B cells (Fig. 1G). However, no significant alteration in somatic hypermutation was detected in immunized $E b f 1^{f l / f 1} R E R T^{C r e}$ mice (Fig. 6D). Finally, we examined the secretion of different classes of antibodies by immunizing tamoxifen-treated mice with either T-cellindependent (TI) antigen (NP-LPS) or TD antigen (NPCGG). Analysis of secreted antibodies by ELISA indicated that the IgM titers were similar in $E b f 1^{+/ f 1}$ and $E b f 1^{f l / f I}$ mice, whereas the levels of IgG3 and IgG1 were reduced in Ebf $1^{f l / f 1}$ mice by a factor of three and a factor of five, respectively (Fig. 6E).

Similar numbers of $\mathrm{CD} 138^{+} \mathrm{CD} 19^{-}$cells were detected in the spleen of $E b f 1^{f l / f 1}$ and $E b f 1^{+/ f 1}$ mice $2 \mathrm{~d}$ after immunization, and the expression of genes characteristic of plasma cells was similar in these cells (Supplemental Fig. S7D,E), suggesting that Ebfl is dispensable for the differentiation of antibody-secreting cells.

\section{Ebf1 regulates $C \gamma 1$ and $C \gamma 3$ germline transcription and binds to the $\operatorname{IgH} 3^{\prime} L C R$}

IgH class switch recombination is dependent on cytokine-induced generation of germline transcription that initiates from intronic promoters that are located upstream of the constant region gene segments (Stavnezer et al. 2008). In addition, class switching requires multiple cycles of cell division and the expression of Aid (Rush et al. 2005; Stavnezer et al. 2008). We examined the generation of GLTs as an early marker for class switch recombination in sorted CD2 $1^{\text {lo }}$ splenic B cells from $E b f 1^{f l / f 1}$ and $E b f^{+/ f l}$ mice because the proliferation defect of Ebf1-deficient B cells precluded an analysis of class switching in vitro (Rush et al. 2005). In unstimulated and LPS-stimulated Ebf1 $1^{f l / f 1}$ cells, the generation of $\gamma 3$ GLTs was markedly impaired (Fig. 7A,B; data not shown). In $E b f 1^{f l / f 1}$ cells stimulated with LPS and IL-4 to favor switching to IgG1 and IgE, we observed a de- crease in $\gamma 1$ GLTs. In contrast, the production of $\gamma 2 B$ GLTs was more efficient in Ebf $1^{f l / f 1}$ cells than in $E b f 1^{+/ f 1}$ cells, suggesting that the response to IL-4 stimulation is not impaired. Stimulation of cells with LPS, in combination with TGF $\beta$ to augment switching to IgG2b, resulted in enhanced generation of $\gamma 2 \mathrm{~B}$ GLT in $E b f 1^{f l / f 1}$ cells (Fig. 7B).

Previous studies determined a pivotal role for the $3^{\prime} \mathrm{E} \alpha$ LCR in the regulation of GLT expression and class switching to most isotypes (Dunnick et al. 2005). Genome-wide ChIP-seq analysis indicated that Ebf1 binds to HS4 and HS7 of the 3' E $\alpha$ LCR already in pro-B cells (Treiber et al. 2010). We confirmed binding of Ebf1 to these sequences in both pro-B cells and mature B cells by quantitative ChIP analysis (Fig. 7C). Regulation of GLT expression also involves changes in the accessibility of chromatin at the I promoters and the LCR (Garrett et al. 2005). Analysis of the acetylation and methylation status of histones $\mathrm{H} 3$ and $\mathrm{H} 4$ at the $\mathrm{IgH}$ constant region in resting and LPS- plus IL-4stimulated splenic B cells showed that $\mathrm{H} 3 \mathrm{~K} 4 \mathrm{me} 2$ and $\mathrm{H} 3 \mathrm{Ac}$ modifications are reduced at the $\gamma 3$ promoter and switch region in Ebf1 ${ }^{f l / f 1}$ cells (Supplemental Fig. S7F). Thus, Ebf1 regulates class switching to $\operatorname{Ig} \gamma 1$ and $\operatorname{Ig} \gamma 3$ by binding to the $3^{\prime}$ LCR and inducing changes in the chromatin structure of the $\gamma 3$ switch region.

\section{Discussion}

B lymphopoiesis requires the coordination of general processes, such as cell proliferation and survival, with a complex program of differentiation, including the activation of a B-cell-specific expression program, immunoglobulin gene rearrangement, BCR signaling, class switch recombination, and terminal differentiation into plasma cells. Transcriptional regulation of these events is governed by elaborate networks of transcription factors. Here, we show that Ebf1 acts as a molecular node in multiple regulatory networks that operate at different developmental stages.
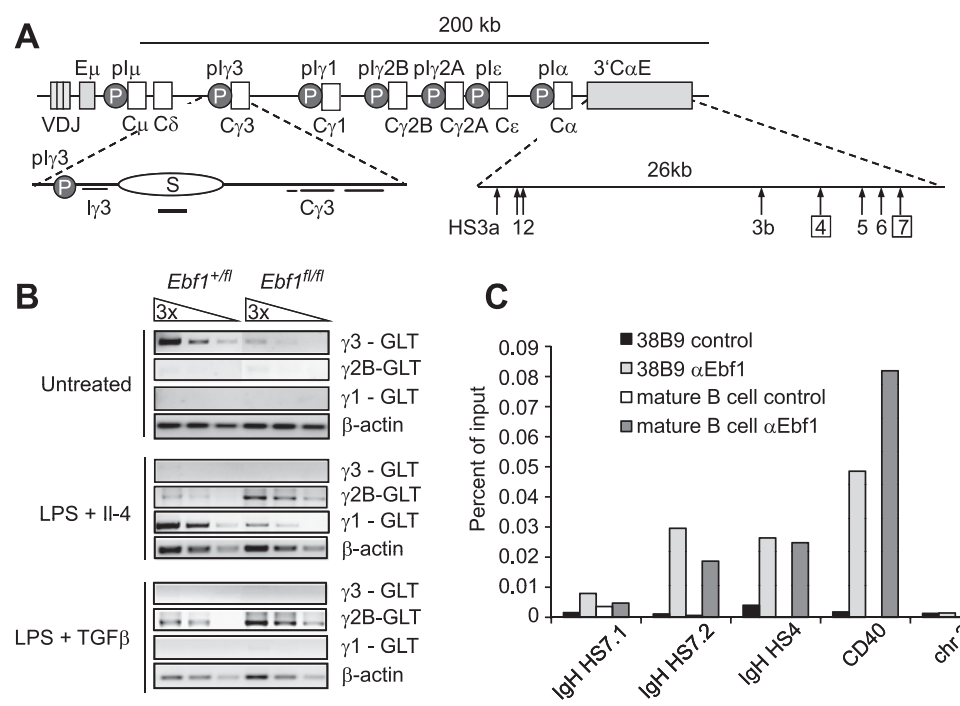

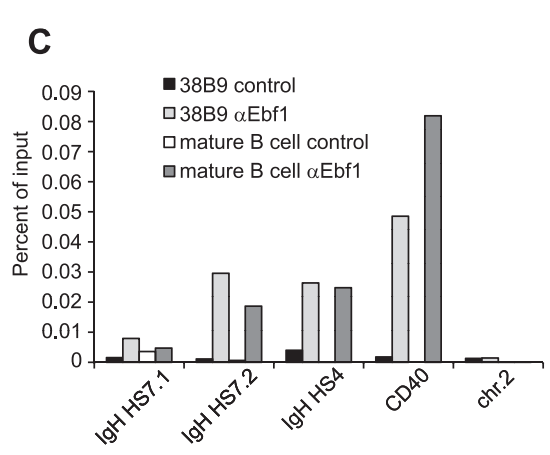

Figure 7. Ebf1 regulates $\gamma 3$ and $\gamma 1$ germline transcription by binding to the $\operatorname{IgH} 3^{\prime} \mathrm{E} \alpha$ LCR. $(A)$ Schematic representation of the IgH locus. Lightgray bars depict rearranged variable gene segments, dark gray bars represent enhancers, and gray circles represent the promoters $(\mathrm{P})$ of the constant region $(\mathrm{C})$ gene segments. The bottom part depicts a magnified view of the $\gamma 3$ gene segment and indicates regulatory sequences, switch (S) region, and 3' E $\alpha$ LCR. DHSs are marked with arrows and numbers. Numbers in squares represent HSs that are directly bound by Ebf1. (B) Semiquantitative RT-PCR analysis of IgH constant region GLTs in unstimulated B cells and B cells stimulated with LPS + IL4 or LPS + TGF $\beta$ for 16 h. (C) ChIP analysis to examine binding of Ebfl in 38B9 pro-B cells or MACS-enriched splenic B cells. Binding is represented as percentage of input chromatin. (See also Supplemental Fig. S7.) 
Györy et al.

\section{Functions of Ebf1 in early stage B cells}

In early stage B cells, Ebf1 exerts functions beyond the previously noted roles in specification and commitment of the lineage (Maier et al. 2004; Medina et al. 2004; Pongubala et al. 2008; Treiber et al. 2010). In particular, Ebf1 regulates cell proliferation and survival, whereby our data suggest that Ebf1 regulates both processes via different targets and pathways. Transformation of Ebf1-deficient pro-B cells with A-MuLV rescues their proliferation defect, but does not overcome their survival defect. Primary Ebf1deficient pro-B cells arrest in G1 of the cell cycle and show impaired expression of direct Ebf1 targets, including the E2F2 and E2F8 transcriptional regulators of the cell cycle, cyclin D3 (Ccnd3), and the replication initiation factor Cdc6. With the exception of Cdc6, these Ebf1 target genes are almost normally expressed in A-MuLV-transformed $E b f 1^{f l / f l}$ pro-B cells. Activated Abl kinase has been found to increase the expression of D-type cyclins and E2F transcription factors (Coutts et al. 2000). Moreover, cyclin D2deficient bone marrow cells fail to proliferate in response to infection with BCR/ABL-expressing retroviruses (Jena et al. 2002). Therefore, A-MuLV-mediated transformation may compensate for the Ebf1 dependence of D cyclins and E2Fs. In B-cell leukemias carrying the $B C R-A B L 1$ chromosomal translocation and in A-MuLV-transformed pro-B cells, cyclin D3 transcription is augmented through the constitutive activation of Stat5 (Mandal et al. 2009; Hoelbl et al. 2010). Thus, cyclin D3 transcription is under the control of both Ebf1 and Stat5. Cyclin D2 and cyclin D3 are abundantly expressed in early stage B cells, and targeted gene inactivation showed that cyclin D3 is preferentially required for pre-B-cell development (Cooper et al. 2006). Moreover, the marked down-regulation of cyclin D3 is required for the proliferative expansion of GC B cells (Cato et al. 2011). However, the marked down-regulation of cyclin D3 in primary Ebf1-deficient pro-B cells alone does not account for their proliferation defect because this defect is not overcome by the forced expression of cyclin D3. Therefore, we favor the view that Ebf1 regulates at least two steps in cell cycle progression: the activation of $\mathrm{D}$ cyclins and the function of an origin activation checkpoint.

The role of Ebf1 in pro-B-cell survival could, in principle, involve the regulation of $I L-7 R \alpha$ by Ebf1 because IL$7 \mathrm{R} \alpha$ signaling and Stat5 expression regulate pro-B-cell survival and prevent $I g \kappa$ rearrangement (Malin et al. 2010). However, it is unlikely that Ebf1-mediated survival of pro-B cells is linked to the function of IL-7R $\alpha$. First, $I L-7 R \alpha$ is indirectly regulated by Ebf1, and second, forced expression of a constitutive form of Stat5 or A-MuLV-mediated transformation failed to overcome the survival defect of Ebf1-deficient pro-B cells. In contrast, forced expression of Bc1211, a direct Ebf1 target, rescued, to a large extent, the survival defect of A-MuLV-transformed Ebf1-deficient pro-B cells. Bcl211 has been implicated in early stage B-cell survival (Fang et al. 1996; Malin et al. 2010). Mcl1 expression is not altered in Ebf1-deficient pro$B$ cells (data not shown), and therefore Bcl211 may act as an Ebf1-regulated determinant of early B-cell survival. How- ever, the survival defect of A-MuLV-transformed Ebf1deficient pro-B cells is even more efficiently rescued by the forced expression of $c-M y b$, which plays a major role in B lymphopoiesis and has been shown to regulate cell survival and IL-7 signaling (Fahl et al. 2009). Myb proteins regulate both $\mathrm{G} 1 / \mathrm{S}$ transition and the $\mathrm{G} 2 / \mathrm{M}$ phase of the cell cycle and act in a complex with E2F and $\mathrm{Rb}$ proteins (Litovchick et al. 2007). Therefore, the overexpression of Myb in transformed Ebf1-deficient pro-B cells may compensate for the impaired expression of E2Fs and phosphorylation of $\mathrm{Rb}$.

Ebf1 has also been implicated in the restriction of alternative cell fates (Pongubala et al. 2008; Lukin et al. 2011). In contrast to gain-of-function experiments or the analysis of a heterozygous germline mutation, we did not observe a major change in the expression of alternative lineage determinants after conditional inactivation of Ebf1. Likewise, the expression of Pax5 and many other prominent Ebf1 targets remained virtually unchanged, suggesting that Ebf1 is required for the establishment but not the maintenance of the B-cell fate. However, we were not able to monitor gene expression during multiple rounds of cell divisions, and therefore it is possible that the expression of Pax 5 and alternative lineage determinants would be unstable in the absence of Ebf1 and deregulated with prolonged cell culture.

The question also arises as to mechanisms by which Ebf1 regulates different genes in pro-B cells and mature B cells. Stage-specific expression in pro-B cells may be accomplished by competitive recruitment of Ikaros, which is up-regulated in mature B cells and binds to a sequence that overlaps with the Ebf1-binding site. The pro-B-cell- and pre-B-cell-specific expression of $\lambda 5$ (Igll1) has been shown to involve a replacement of promoter-bound Ebf1 by Ikaros proteins at later stages of differentiation (Thompson et al. 2007). By ChIP-seq analysis, we could confirm the loss of Ebf1 binding in mature B cells (see Fig. 5C). Conversely, we found that many B-cell-specific genes are bound by Ebf1 specifically in mature B cells, suggesting that the Ebf1-binding site is not accessible due to competitive binding of a repressor or nonpermissive chromatin structure. We showed previously that Ebf1 binding requires a permissive chromatin context (Treiber et al. 2010). Therefore, we favor the view that in genes specifically bound by Ebf 1 in mature B cells, a permissive chromatin context is generated by the binding and/or function of collaborating transcription factors specifically in B cells.

\section{Functions of Ebf1 in mature and GC B cells}

At the mature B-cell stage, Ebf1 is also required for proliferation and survival of stimulated cells. Stimulation of $E b f 1^{f l / f 1} \mathrm{~B}$ cells with LPS, CpG, or anti-IgM fails to induce proliferation, as determined by dilution of CFSE and incorporation of EDU. As these stimuli act via different signaling pathways, we conclude that the inactivation of Ebf1 results in a proliferation and survival defect, rather than in a defect in cell stimulation. Similar to early stage B cells, the effects of Ebf1 inactivation on the survival of ma- 
ture B cells is less pronounced than that observed in proB cells. Survival of resting B cells is regulated by the BAFF-R and PI3K signaling pathways (Kraus et al. 2004; Mecklenbrauker et al. 2004; Srinivasan et al. 2009). In Ebf1-deficient B cells, the surface expression of BAFF-R is diminished, and we observed a modest rescue of the survival defect by the addition of excess BAFF. We also observed a marked defect of Akt phosphorylation in anti-BCR-stimulated Ebf1-deficient B cells. However, Ebf1 may be dispensable for tonic BCR/Akt signaling, as we observed neither changes in the number of resting Ebf1-deficient B cells nor alterations in the expression of genes associated with tonic Akt signaling (Supplemental Fig. S4E; Srinivasan et al. 2009).

Many components of the (pre-)BCR signaling pathway were previously identified in genome-wide ChIP-seq analyses as Ebf1-bound targets (Lin et al. 2010; Treiber et al. 2010). Consistent with a role of Ebf1 in BCR signaling, we observed defects in $\mathrm{Ca}^{2+}$ mobilization and tyrosine phosphorylation of anti-IgM-stimulated Ebf1-deficient B cells. In these cells, we observed reduced phosphorylation of $\operatorname{Ig} \alpha(\mathrm{Cd} 79 \mathrm{a})$, despite normal protein expression. Moreover, we detected a reduction of tyrosine phosphorylation of Cd19 that exceeded the modest twofold decrease in Cd19 RNA and protein expression. CD19 plays an important role in B-cell activation by regulating the formation of BCR microclusters (Depoil et al. 2008). Therefore, it is possible that Ebf1-deficient B cells show a more pronounced defect in canonical BCR signaling in the context of membrane-bound ligands. In anti-IgMstimulated Ebf1-deficient B cells, the expression of the Src family kinase Lyn was normal, but we detected a marked decrease of the expression of the Src family kinase gene Blk. We also examined the expression of Ebfl targets implicated in the regulation of the PI3K arm of the BCR. Although many components of the Akt signaling pathway, including the catalytic and regulatory subunits of PI3K, Pik3cy, Pik3, Pik3r1, and Pik3r5, as well as the adaptor $\mathrm{BCAP}$, are bound by Ebf1, we only detect a deregulation of Pik3c2b (Supplemental Tables S2, S5A; Treiber et al. 2010). Consistent with a BCR-proximal defect of Akt signaling, the decrease in CD19 surface expression and phosphorylation could account for an impaired recruitment of PI3K to the BCR. However, most Ebfl targets in the BCR pathway are only modestly deregulated in Ebf1-deficient B cells, suggesting that Ebf1 plays an important role in the establishment but not the maintenance of the BCR and Akt signaling pathways.

The reduced phosphorylation of Akt and impaired $\mathrm{Ca}^{2+}$ mobilization in anti-IgM-stimulated $E b f 1^{f l / f 1} \mathrm{~B}$ cells is reminiscent of the defects observed in B cells from Foxo $1^{\text {fl/f }}$ mice. Although Foxo1 expression is reduced in Ebf1-deficient pro-B cells, no changes in Foxo1 and Foxo3 expression are observed in mature Ebf1-deficient B cells. Ebf1 $1^{f l / f l}$ and Foxo $1^{f l / f l} \mathrm{~B}$ cells differ in the proliferative response to stimulation with LPS and the defects in GC B-cell functions (Dengler et al. 2008). In particular, Foxol regulates the expression of Aicda, but does not affect locus accessibility and germline transcription of constant region segments (Dengler et al. 2008). In contrast, Ebf1 does not regulate
Aicda expression, but is required for the generation of $\mathrm{C} \gamma 1$ and C $\gamma 3$ GLTs. Thus, Ebf1 and Foxo1, which coregulate many genes in early stage B cells (Lin et al. 2010), appear to have only partially overlapping functions in mature B cells.

In summary, our analysis showed that Ebf1 regulates a diverse set of processes in early and late stages of B-cell differentiation. By regulating important components of transcription factor and signaling networks, Ebf1 may act as a molecular node that helps to coordinate proliferation, survival, and differentiation of B-lineage cells.

\section{Materials and methods}

Generation of $E b f 1^{+/ f 1}$ mice

The targeting construct was designed to introduce loxP sites flanking exons 2 and 3, which encode part of the DNA-binding domain. The flanks and "deletable" fragment of the Ebf1 gene were PCR-cloned with the Expand High-Fidelity PCR system (Roche) using genomic DNA from D3V embryonic stem cells as a template. The targeting vector allowed the FLP recombinase-mediated excision of the neomycin selection cassette (gift of R. Fässler). Chimeras were obtained after injection of the targeted embryonic D3V stem cell clones into blastocysts derived from C57BL/6 mice. The chimeras were crossed with C57BL/6 $6^{\text {ACTFLPe }}$ mice (Rodriguez et al. 2000) to generate an frt-Neo-null allele, referred to as $E b f 1^{+/ f l}$ mice.

\section{Induced deletion of Ebf1 in vitro and in vivo}

$E b f 1^{+/ f 1}$ and $E b f 1^{f l / f l} R E R T^{\text {Cre }}$ fetal liver pro-B cells were cultured as described (Treiber et al. 2010). For inactivation of $E b f 1$, the $\mathrm{B}$ cells were treated with $2 \mu \mathrm{M}$ 4-hydroxy-tamoxifen for $24 \mathrm{~h}$, washed, and cultured for an additional $4 \mathrm{~d}$. Three independent cultures of each genotype were analyzed for their survival and gene expression pattern. The oral gavage method of tamoxifencitrate administration was performed as described (Hobeika et al. 2006). $E b f 1^{+/ f 1} R E R T^{C r e}$ and $E b f 1^{f l / f l} R E R T^{C r e}$ mice received $3 \mathrm{mg}$ of tamoxifen-citrate on four consecutive days and were immunized or sacrificed for analysis on the 10th day after the start of the tamoxifen treatment.

\section{Expression profiling and quantitative RT-PCR}

For expression profiling, $\mathrm{B} 220^{+} \mathrm{AA} 4.1^{-}$and $\mathrm{B} 220^{+} \mathrm{AA} 4.1^{-} \mathrm{CD} 21^{\text {lo }}$ splenic B cells were sorted from tamoxifen-treated $E b f 1^{+/ f l} R E R T^{C r e}$ and $E b f 1^{\mathrm{fl} / / \mathrm{l}} R E R T^{\mathrm{Cre}}$ mice in triplicates, and total RNA was prepared using the RNeasy minikit (Qiagen) according to the manufacturer's protocol. Labeling, hybridization to the Agilent Technologies Microarray Agilent-014868 4x44K, and standard analysis of gene expression were performed by ImaGenes.

For quantitative RT-PCR analysis, RNA was prepared using Trizol reagent (Invitrogen) according to the manufacturer's instructions. SuperScript II Reverse Transcriptase (Invitrogen) was used to reverse-transcribe $500 \mathrm{ng}$ of RNA. Real-time RT-PCR was performed using Power SYBR Green master mix and a 7500 Fast Real-Time PCR system (Applied Biosystems). All quantitative PCR primer sequences are available on request.

\section{Immunization and plasma cell analysis}

SRBCs $\left(5 \times 10^{8}\right.$ cells $)$, NP-CGG, or NP-LPS $(100 \mu \mathrm{g}$ in Alum) were intraperitoneally injected into adult $E b f 1^{+/ f 1}$ and $E b f 1^{f l / f 1}$ mice. Serum immunoglobulin titers were determined by enzyme-linked immunosorbant (ELISA) assays. Plasma cells were FACS-sorted and analyzed after $3 \mathrm{~d}$ of SRBC immunization. 
ChIP

Anti-EBF ChIP was performed as previously described (Pongubala et al. 2008). The histone modification analysis was performed as previously described (Gyory et al. 2004). Antibodies specific for histone modifications were anti-H3K4me3 (Abcam, \#8580), anti-H3K4me2 (Millipore, \#07-030), anti-acetyl H3 (Millipore, \#06-599), and anti-acetyl H4 (Millipore, \#06-598).

\section{Generation and analysis of ChIP-seq libraries}

ChIP-seq libraries in splenic B cells were prepared as previously described (Treiber et al. 2010) and sequenced on the Illumina Genome Analyzer platform. The Ebf1 ChIP-seq library was processed as described, and Ebf1-binding regions in pro-B cells (data from Treiber et al. 2010) and splenic B cells (this study) were identified using CCAT with default settings (version 3.0) (Xu et al. 2010). A high-confidence subset of binding sites was obtained by retaining the top $25 \%$ most-enriched peaks of each library. H3K4me2 and H3K4me3 ChIP-seq data in pro-B cells (Lin et al. 2010; obtained from http://biowhat.ucsd.edu/homer/ data/index.html), H3K4me2 and H3K4me3 ChIP-seq data in splenic B cells (this study), and DHS sequencing data in murine CD19+ $\mathrm{B}$ cells and naive $\mathrm{T}$ cells (downloaded from http:// genome.ucsc.edu/ENCODE; Sabo et al. 2006) were mapped using Bowtie (Langmead et al. 2009). All libraries were aligned to the mouse reference genome (mm8, NCBI build 36). BedGraph files of each sequencing library were generated using Homer with default settings for visualization of sequencing data on the University of California at Santa Cruz (UCSC) Genome Browser. All libraries were normalized to 10 million reads.

H3K4me2 modifications at Ebf1-binding sites in splenic B cells were assessed by generating a histogram of normalized $\mathrm{H} 3 \mathrm{~K} 4 \mathrm{me} 2$ tag counts across 6-kb intervals in 25-base-pair (bp) bins around Ebf1-binding sites using Homer. Binding regions were clustered with Cluster 3.0 and visualized with Java TreeView.

The data mentioned in this study have been deposited in NCBI's Gene Expression Omnibus (GEO) and are accessible through GSE36061, which includes ChIP-seq data (GSE35915) and gene expression microarray data (GSE36061). Data may be viewed at http://www.ncbi.nlm.nih.gov/geo/query/acc.cgi?acc=GSE36061.

\section{Acknowledgments}

We thank Drs. Klaus Rajewsky and Stefano Casola for generously providing the C $\gamma 1$-Cre and CD21-Cre mouse strains. We are grateful to Drs. Michael Reth, Klaus Rajewsky, and Alan Harris for providing the mb1-Cre, Cd19-Cre, and TgBcl2 mouse strains, respectively. We thank Ingrid Falk and Stefanie Fietze for their expert technical help, and Elias Hobeika and Hassan Jumaa for stimulating discussions.

\section{References}

Amin RH, Schlissel MS. 2008. Foxol directly regulates the transcription of recombination-activating genes during B cell development. Nat Immunol 9: 613-622.

Bain G, Maandag EC, Izon DJ, Amsen D, Kruisbeek AM, Weintraub BC, Krop I, Schlissel MS, Feeney AJ, van Roon M, et al. 1994. E2A proteins are required for proper B cell development and initiation of immunoglobulin gene rearrangements. Cell 79: 885-892.

Beck K, Peak MM, Ota T, Nemazee D, Murre C. 2009. Distinct roles for E12 and E47 in B cell specification and the sequential rearrangement of immunoglobulin light chain loci. J Exp Med 206: $2271-2284$.
Casola S, Cattoretti G, Uyttersprot N, Koralov SB, Seagal J, Hao Z, Waisman A, Egert A, Ghitza D, Rajewsky K. 2006. Tracking germinal center B cells expressing germline immunoglobulin $\gamma 1$ transcripts by conditional gene targeting. Proc Natl Acad Sci 103: 7396-7401.

Cato MH, Chintalapati SK, Yau IW, Omori SA, Rickert RC. 2011. Cyclin D3 is selectively required for proliferative expansion of germinal center B cells. Mol Cell Biol 31: $127-137$.

Cheng S, Hsia CY, Leone G, Liou HC. 2003. Cyclin E and Bcl-xL cooperatively induce cell cycle progression in $\mathrm{c}^{-\mathrm{Rel}^{-/-}} \mathrm{B}$ cells. Oncogene 22: 8472-8486.

Cooper AB, Sawai CM, Sicinska E, Powers SE, Sicinski P, Clark MR, Aifantis I. 2006. A unique function for cyclin D3 in early B cell development. Nat Immunol 7: 489-497.

Coutts M, Zou X, Calame K. 2000. v-Abl utilizes multiple mechanisms to drive $\mathrm{G} 1 / \mathrm{S}$ progression in fibroblasts. Oncogene 19: 801-809.

Danial NN, Pernis A, Rothman PB. 1995. Jak-STAT signaling induced by the v-abl oncogene. Science 269: 1875-1877.

Dengler HS, Baracho GV, Omori SA, Bruckner S, Arden KC, Castrillon DH, DePinho RA, Rickert RC. 2008. Distinct functions for the transcription factor Foxol at various stages of B cell differentiation. Nat Immunol 9: 1388-1398.

Depoil D, Fleire S, Treanor BL, Weber M, Harwood NE, Marchbank KL, Tybulewicz VL, Batista FD. 2008. CD19 is essential for B cell activation by promoting $\mathrm{B}$ cell receptor-antigen microcluster formation in response to membrane-bound ligand. Nat Immunol 9: 63-72.

Dias S, Silva H Jr, Cumano A, Vieira P. 2005. Interleukin-7 is necessary to maintain the $\mathrm{B}$ cell potential in common lymphoid progenitors. J Exp Med 201: 971-979.

Dunnick WA, Shi J, Graves KA, Collins JT. 2005. The 3' end of the heavy chain constant region locus enhances germline transcription and switch recombination of the four $\gamma$ genes. J Exp Med 201: 1459-1466.

Fahl SP, Crittenden RB, Allman D, Bender TP. 2009. c-Myb is required for pro-B cell differentiation. J Immunol 183: 55825592.

Fang W, Mueller DL, Pennell CA, Rivard JJ, Li YS, Hardy RR, Schlissel MS, Behrens TW. 1996. Frequent aberrant immunoglobulin gene rearrangements in pro-B cells revealed by a bcl-xL transgene. Immunity 4: 291-299.

Fischer MB, Goerg S, Shen L, Prodeus AP, Goodnow CC, Kelsoe G, Carroll MC. 1998. Dependence of germinal center B cells on expression of CD21/CD35 for survival. Science 280: 582585.

Garrett FE, Emelyanov AV, Sepulveda MA, Flanagan P, Volpi S, Li F, Loukinov D, Eckhardt LA, Lobanenkov VV, Birshtein BK. 2005. Chromatin architecture near a potential $3^{\prime}$ end of the igh locus involves modular regulation of histone modifications during B-cell development and in vivo occupancy at CTCF sites. Mol Cell Biol 25: 1511-1525.

Greig KT, de Graaf CA, Murphy JM, Carpinelli MR, Pang SH, Frampton J, Kile BT, Hilton DJ, Nutt SL. 2010. Critical roles for c-Myb in lymphoid priming and early B-cell development. Blood 115: 2796-2805.

Grillot DA, Merino R, Pena JC, Fanslow WC, Finkelman FD, Thompson CB, Nunez G. 1996. bcl-x exhibits regulated expression during $\mathrm{B}$ cell development and activation and modulates lymphocyte survival in transgenic mice. I Exp Med 183: 381-391.

Guerra C, Mijimolle N, Dhawahir A, Dubus P, Barradas M, Serrano M, Campuzano V, Barbacid M. 2003. Tumor induction by an endogenous K-ras oncogene is highly dependent on cellular context. Cancer Cell 4: 111-120. 
Gyory I, Wu J, Fejer G, Seto E, Wright KL. 2004. PRDI-BF1 recruits the histone $\mathrm{H} 3$ methyltransferase G9a in transcriptional silencing. Nat Immunol 5: 299-308.

Herzog S, Hug E, Meixlsperger S, Paik JH, DePinho RA, Reth M, Jumaa H. 2008. SLP-65 regulates immunoglobulin light chain gene recombination through the PI(3)K-PKB-Foxo pathway. Nat Immunol 9: 623-631.

Hobeika E, Thiemann S, Storch B, Jumaa H, Nielsen PJ, Pelanda R, Reth M. 2006. Testing gene function early in the B cell lineage in mb1-cre mice. Proc Natl Acad Sci 103: 1378913794.

Hoelbl A, Schuster C, Kovacic B, Zhu B, Wickre M, Hoelzl MA, Fajmann S, Grebien F, Warsch W, Stengl G, et al. 2010. Stat5 is indispensable for the maintenance of bcr/abl-positive leukaemia. EMBO Mol Med 2: 98-110.

Horcher M, Souabni A, Busslinger M. 2001. Pax5/BSAP maintains the identity of B cells in late B lymphopoiesis. Immunity 14: 779-790.

Jena N, Deng M, Sicinska E, Sicinski P, Daley GQ. 2002. Critical role for cyclin D2 in BCR/ABL-induced proliferation of hematopoietic cells. Cancer Res 62: 535-541.

Johnson K, Hashimshony T, Sawai CM, Pongubala JM, Skok JA, Aifantis I, Singh H. 2008. Regulation of immunoglobulin light-chain recombination by the transcription factor IRF-4 and the attenuation of interleukin-7 signaling. Immunity 28: 335-345.

Kerdiles YM, Beisner DR, Tinoco R, Dejean AS, Castrillon DH, DePinho RA, Hedrick SM. 2009. Foxol links homing and survival of naive $\mathrm{T}$ cells by regulating L-selectin, CCR7 and interleukin 7 receptor. Nat Immunol 10: 176-184.

Klein U, Dalla-Favera R. 2008. Germinal centres: Role in B-cell physiology and malignancy. Nat Rev Immunol 8: 22-33.

Kraus M, Alimzhanov MB, Rajewsky N, Rajewsky K. 2004. Survival of resting mature B lymphocytes depends on BCR signaling via the $\operatorname{Ig} \alpha / \beta$ heterodimer. Cell 117: 787-800.

Kwon K, Hutter C, Sun Q, Bilic I, Cobaleda C, Malin S, Busslinger M. 2008. Instructive role of the transcription factor E2A in early B lymphopoiesis and germinal center B cell development. Immunity 28: 751-762.

Langmead B, Trapnell C, Pop M, Salzberg SL. 2009. Ultrafast and memory-efficient alignment of short DNA sequences to the human genome. Genome Biol 10: R25. doi: 10.1186/gb-200910-3-r25.

Lazorchak AS, Schlissel MS, Zhuang Y. 2006. E2A and IRF-4/Pip promote chromatin modification and transcription of the immunoglobulin $\kappa$ locus in pre-B cells. Mol Cell Biol 26: 810-821.

Lin H, Grosschedl R. 1995. Failure of B-cell differentiation in mice lacking the transcription factor EBF. Nature 376: 263-267.

Lin YC, Jhunjhunwala S, Benner C, Heinz S, Welinder E, Mansson R, Sigvardsson M, Hagman J, Espinoza CA, Dutkowski J, et al. 2010. A global network of transcription factors, involving E2A, EBF1 and Foxo1, that orchestrates B cell fate. Nat Immunol 11: 635-643.

Litovchick L, Sadasivam S, Florens L, Zhu X, Swanson SK, Velmurugan S, Chen R, Washburn MP, Liu XS, DeCaprio JA. 2007. Evolutionarily conserved multisubunit RBL2/p130 and E2F4 protein complex represses human cell cycle-dependent genes in quiescence. Mol Cell 26: 539-551.

Lu R, Medina KL, Lancki DW, Singh H. 2003. IRF-4,8 orchestrate the pre-B-to-B transition in lymphocyte development. Genes Dev 17: 1703-1708.

Lukin K, Fields S, Guerrettaz L, Straign D, Rodriguez V, Zandi S, Mansson R, Cambier JC, Sigvardsson M, Hagman J. 2011. A dose-dependent role for EBF1 in repressing non-B-cell-specific genes. Eur I Immunol 41: 1787-1793.
Maier H, Ostraat R, Gao H, Fields S, Shinton SA, Medina KL, Ikawa T, Murre C, Singh H, Hardy RR, et al. 2004. Early B cell factor cooperates with Runxl and mediates epigenetic changes associated with mb-1 transcription. Nat Immunol 5: 1069-1077.

Malin S, McManus S, Cobaleda C, Novatchkova M, Delogu A, Bouillet P, Strasser A, Busslinger M. 2010. Role of STAT5 in controlling cell survival and immunoglobulin gene recombination during pro-B cell development. Nat Immunol 11: 171-179.

Mandal M, Powers SE, Ochiai K, Georgopoulos K, Kee BL, Singh H, Clark MR. 2009. Ras orchestrates exit from the cell cycle and light-chain recombination during early B cell development. Nat Immunol 10: 1110-1117.

Mandel EM, Grosschedl R. 2010. Transcription control of early B cell differentiation. Curr Opin Immunol 22: 161-167.

Mecklenbrauker I, Kalled SL, Leitges M, Mackay F, Tarakhovsky A. 2004. Regulation of B-cell survival by BAFF-dependent PKCס-mediated nuclear signalling. Nature 431: 456-461.

Medina KL, Pongubala JM, Reddy KL, Lancki DW, Dekoter R, Kieslinger M, Grosschedl R, Singh H. 2004. Assembling a gene regulatory network for specification of the $\mathrm{B}$ cell fate. Dev Cell 7: 607-617.

Nutt SL, Kee BL. 2007. The transcriptional regulation of B cell lineage commitment. Immunity 26: 715-725.

Okkenhaug K, Fruman DA. 2010. PI3Ks in lymphocyte signaling and development. Curr Top Microbiol Immunol 346: 57-85.

Parada Y, Banerji L, Glassford J, Lea NC, Collado M, Rivas C, Lewis JL, Gordon MY, Thomas NS, Lam EW. 2001. BCR-ABL and interleukin 3 promote haematopoietic cell proliferation and survival through modulation of cyclin D2 and p27Kip1 expression. J Biol Chem 276: 23572-23580.

Pongubala JM, Northrup DL, Lancki DW, Medina KL, Treiber T, Bertolino E, Thomas M, Grosschedl R, Allman D, Singh H. 2008. Transcription factor EBF restricts alternative lineage options and promotes B cell fate commitment independently of Pax5. Nat Immunol 9: 203-215.

Quong MW, Martensson A, Langerak AW, Rivera RR, Nemazee D, Murre C. 2004. Receptor editing and marginal zone B cell development are regulated by the helix-loop-helix protein, E2A. J Exp Med 199: 1101-1112.

Reynaud D, Demarco IA, Reddy KL, Schjerven H, Bertolino E, Chen Z, Smale ST, Winandy S, Singh H. 2008. Regulation of $B$ cell fate commitment and immunoglobulin heavy-chain gene rearrangements by Ikaros. Nat Immunol 9: 927-936.

Rickert RC, Roes J, Rajewsky K. 1997. B lymphocyte-specific, Cre-mediated mutagenesis in mice. Nucleic Acids Res 25: 1317-1318.

Rodriguez CI, Buchholz F, Galloway J, Sequerra R, Kasper J, Ayala R, Stewart AF, Dymecki SM. 2000. High-efficiency deleter mice show that FLPe is an alternative to Cre-loxP. Nat Genet 25: 139-140.

Rush JS, Liu M, Odegard VH, Unniraman S, Schatz DG. 2005. Expression of activation-induced cytidine deaminase is regulated by cell division, providing a mechanistic basis for division-linked class switch recombination. Proc Natl Acad Sci 102: 13242-13247.

Sabo PJ, Kuehn MS, Thurman R, Johnson BE, Johnson EM, Cao H, Yu M, Rosenzweig E, Goldy J, Haydock A, et al. 2006. Genome-scale mapping of DNase I sensitivity in vivo using tiling DNA microarrays. Nat Methods 3: 511-518.

Srinivasan L, Sasaki Y, Calado DP, Zhang B, Paik JH, DePinho RA, Kutok JL, Kearney JF, Otipoby KL, Rajewsky K. 2009. PI3 kinase signals BCR-dependent mature B cell survival. Cell 139: $573-586$. 
Györy et al.

Stavnezer J, Guikema JE, Schrader CE. 2008. Mechanism and regulation of class switch recombination. Annu Rev Immunol 26: 261-292.

Thal MA, Carvalho TL, He T, Kim HG, Gao H, Hagman J, Klug CA. 2009. Ebf1-mediated down-regulation of $\operatorname{Id} 2$ and $\operatorname{Id} 3$ is essential for specification of the B cell lineage. Proc Natl Acad Sci 106: 552-557.

Thomas MD, Kremer CS, Ravichandran KS, Rajewsky K, Bender TP. 2005. c-Myb is critical for B cell development and maintenance of follicular B cells. Immunity 23: 275-286.

Thompson EC, Cobb BS, Sabbattini P, Meixlsperger S, Parelho V, Liberg D, Taylor B, Dillon N, Georgopoulos K, Jumaa H, et al 2007. Ikaros DNA-binding proteins as integral components of B cell developmental-stage-specific regulatory circuits. Immunity 26: 335-344.

Treiber T, Mandel EM, Pott S, Gyory I, Firner S, Liu ET, Grosschedl R. 2010. Early B cell factor 1 regulates B cell gene networks by activation, repression, and transcriptionindependent poising of chromatin. Immunity 32: 714-725.

Tudzarova S, Trotter MW, Wollenschlaeger A, Mulvey C, GodovacZimmermann J, Williams GH, Stoeber K. 2010. Molecular architecture of the DNA replication origin activation checkpoint. EMBO I 29: 3381-3394.

Wakatsuki Y, Neurath MF, Max EE, Strober W. 1994. The B cellspecific transcription factor BSAP regulates B cell proliferation. J Exp Med 179: 1099-1108.

Wang H, Beaty N, Chen S, Qi CF, Masiuk M, Shin DM, Morse HC III. 2012. The CXCR7 chemokine receptor promotes $\mathrm{B}$-cell retention in the splenic marginal zone and serves as a sink for CXCL12. Blood 119: 465-468.

Werner M, Hobeika E, Jumaa H. 2010. Role of PI3K in the generation and survival of B cells. Immunol Rev 237: 55-71.

Wolniak KL, Shinall SM, Waldschmidt TJ. 2004. The germinal center response. Crit Rev Immunol 24: 39-65.

Xu H, Handoko L, Wei X, Ye C, Sheng J, Wei CL, Lin F, Sung WK. 2010. A signal-noise model for significance analysis of ChIP-seq with negative control. Bioinformatics 26: 11991204.

Zandi S, Mansson R, Tsapogas P, Zetterblad J, Bryder D, Sigvardsson M. 2008. EBF1 is essential for B-lineage priming and establishment of a transcription factor network in common lymphoid progenitors. I Immunol 181: 3364-3372.

Zhang Z, Cotta CV, Stephan RP, deGuzman CG, Klug CA. 2003. Enforced expression of EBF in hematopoietic stem cells restricts lymphopoiesis to the B cell lineage. EMBO I 22: 47594769.

Zhuang Y, Soriano P, Weintraub H. 1994. The helix-loop-helix gene E2A is required for B cell formation. Cell 79: 875-884. 


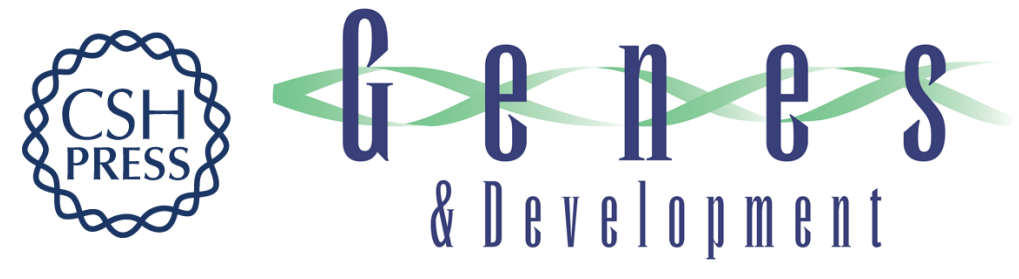

\section{Transcription factor Ebf1 regulates differentiation stage-specific signaling, proliferation, and survival of B cells}

Ildiko Györy, Sören Boller, Robert Nechanitzky, et al.

Genes Dev. 2012, 26: originally published online March 19, 2012

Access the most recent version at doi:10.1101/gad.187328.112

\section{Supplemental http://genesdev.cshlp.org/content/suppl/2012/03/12/gad.187328.112.DC1 Material}

References This article cites 69 articles, 25 of which can be accessed free at: http://genesdev.cshlp.org/content/26/7/668.full.html\#ref-list-1

License Freely available online through the Genes \& Development Open Access option.
Email Alerting Service

